\title{
Information Infrastructure for Air Quality Modeling and Analysis: Application to the Houston-Galveston Ozone Non-attainment Area
}

\author{
D. W. Byun*, S. T. Kim, F. Y. Cheng, S. B. Kim, A. Cuclis and N. K. Moon \\ Institute for Multi-dimensional Air Quality Studies, University of Houston, \\ 312 Science and Research Building 1, Houston, TX 77204-5007, USA
}

\begin{abstract}
The Houston-Galveston Area (HGA) and several other metropolitan regions in the US are classified, under the Clean Air Act, as non-attainment areas because of the noncompliance of air quality standards due to higher ground-level ozone and particulate matter concentrations. These regions must reduce their ozone levels within the next 5 to 7 years to comply with EPA standards or they will be penalized with a loss of federal funding and other punitive measures. To study the severity of air pollution problems and to provide tools for the development of emissions control strategies, a research information infrastructure that includes air quality measurement data and various modeling systems is necessary. This paper presents an example of such system that integrates a set of meteorological models, emissions processing systems, air quality models, a trajectory analysis tool, a GIS-based data analysis/visualization system, and a collection of observational data sets for the HGA housed in a network of computer systems. We demonstrate the capacity and utilization potential of the information infrastructure to test some of the nongovernmental organizations and public initiated emissions control scenarios proposed by groups including the Task Force for Ozone Reduction Strategies (TFORS), which might have a significant impact on the State Implementation Plan (SIP).
\end{abstract}

Keywords: Air quality modeling, emissions, meteorological modeling, ozone, state implementation plan

\section{Introduction}

The Houston-Galveston Area (HGA) contains about 50\% of the nation's petrochemical production capacity: 27.6 billion pounds of ethylene (i.e., $52 \%$ of the nation's capacity) and 10.9 billion pounds of polymer grade propylene $(63 \%$ of the nation's capacity). Some of the emissions from petrochemical facilities and a considerable amount of mobile emissions in the metropolitan area create serious air quality problems as they are respiratory irritants causing significant health effects and are suspected of elevating cancer risks to certain populations. HGA became one of the most severe ozone non-attainment regions in the US during the years 1999-2000 for both 1-hour ozone and the number of high ozone days (U.S. EPA; http://www.epa.gov/oar/ oaqps/greenbk). Nitrogen oxides from the internal combustion engines and various volatile organic compounds (VOCs) emitted by natural and anthropogenic sources are precursors of ozone and particulate pollutants that are regulated according to the National Ambient Air Quality Standards (NAAQS). Several different measurements taken during the Texas Air Quality Study (TexAQS2000; http://www.utexas.edu/research/ceer/ texaqs/ participants/about.html) have demonstrated a frequent and

\footnotetext{
* Corresponding author: dbyun@mail.uh.edu
}

rapid increase of ozone concentrations (increases of over 20 ppb per hour) in the HGA. The air trajectory analysis shows that the problem is exacerbated when ozone precursor emissions are sent out to the Galveston Bay and Gulf areas by the land breezes in the morning then returned by the sea breezes in the afternoon. To minimize the occurrence of such high ozone events, the VOC and $\mathrm{NO}_{\mathrm{x}}$ (sum of $\mathrm{NO}$ and $\mathrm{NO}_{2}$ ) emissions from point, mobile and area sources may need to be reduced. Several other cities in the US and other countries may have similar air quality problems that needed to be studied.

In order to understand the physical and chemical processes that determine air quality and to study the effects of emissions from the natural and man-made sources, predictive numerical models have been used extensively. These environmental models require comprehensive and multidisciplinary information infrastructure to provide necessary inputs that characterize the environmental conditions, compare the simulation results with observations, perform the what-if sensitivity studies, and archive important model outputs for future analysis. In this paper, we introduce an example of such modeling and analysis infrastructure that integrates meteorological modeling, emissions processing, air quality modeling, and observation-model evaluation. Also, we provide some application examples to study ozone nonattainment problems in the Houston-Galveston Area. 


\section{Assembly of Air Quality Modeling System Components for the Environmental Information Infrastructure}

To provide extensive air quality modeling capabilities, we have incorporated a modeling paradigm that combines different meteorological models, two emission inventory models, and two chemical transport models, along with assorted supporting pre- and inter-processing programs. The primary analysis tools are based on the Community Multiscale Air Quality (CMAQ) modeling system (Byun and Ching, 1999), which is the latest Eulerian air quality model made available by the U.S. EPA. CMAQ employs the best available techniques for advection, diffusion, and complex chemical transformation of a variety of pollutants. The system consists of three primary components (meteorology, emissions, and a chemical transport model) and several interface processors. Figure 1 illustrates the relationship between the CMAQ processors and the requisite interfaces with the chemical transport model. With this structure, CMAQ retains the flexibility to substitute other emissions modeling systems and meteorological models. In the current release, the Sparse Matrix Operator Kernel Emission (SMOKE; Coats, 1996; Houyoux et al., 2000) model is used to produce the model-ready emissions data and the Fifth Generation Penn State University/National Center for Atmospheric Research Mesoscale Model (MM5) (Grell et al., 1994) provides the meteorological fields needed for the CMAQ Chemical Transport Model (hereafter, CTM). The CMAQ CTM (CCTM) is designed for multi-pollutant and multi-scale air quality modeling, from very small scales (such as urban areas) to very large scales (such as the US continent). CMAQ uses a generalized coordi- nate system, which makes it flexible to work with most known Eulerian systems as long as the Jacobian of transformation is available. Mass consistency is one of the most important features for transport and transformation of air pollutants. For that reason mass consistency is constantly monitored in the model during calculations. In cases of inconsistencies in the input, different algorithms for mass adjustment are available.

A set of preprocessors provides linkage mechanisms among the meteorology, emissions, and chemistry transport modeling components. These processors include: the Emission-Chemistry Interface Processor (ECIP) that translates data from the SMOKE emission model for use in the CCTM; the Plume Dynamics Model that computes geometry of subgrid scale Lagrangian plumes for large elevated emitters; and the Meteorology-Chemistry Interface Processor (MCIP) that translates and processes outputs from the meteorology model for the CCTM. Initial condition and boundary condition processors (IC/BC Proc) provide concentration fields for individual chemical species for the beginning of a simulation and for the grids surrounding the modeling domain, respectively, and the photolysis processor (JPROC) calculates temporally varying photolysis rates. The arrows in Figure 1 show the flow of data through the modeling system.

In addition to the MM5 modeling system, other meteorological models - such as the Weather Research and Forecasting (WRF) model (Klemp et al., 2000), which is a next-generation mesoscale modeling system to replace MM5; and the CALMET model (Scire et al., 2000), which provides a mechanism further downscaling meteorology beyond the current limit of mesoscale models - are also applicable in this framework. We also include an alternative emissions proces-

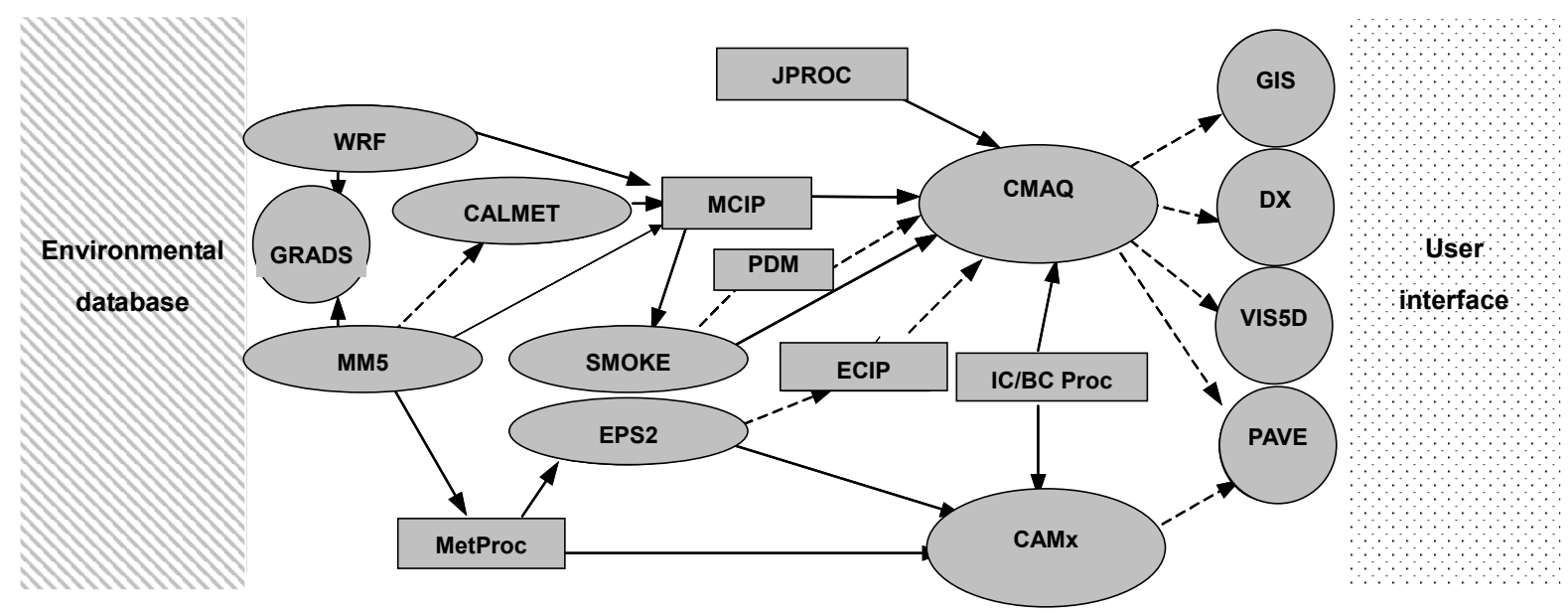

Note: The air quality information infrastructure includes various modeling systems, analysis tools, and several different environmental input databases. Solid lines represent primary data flows and dashed lines are for alternative processing sequences. Oval symbols are for the science models, small rectangles are for the interface processors, and circles represent analysis and visualization systems (GRADS, GIS, DX, Vis5D, and PAVE). Solid lines represent the essential data linkage and arrows represent directions of the flows of information. Dashed lines represent optional data flow. Many of linkages among the processors and data are built at the University of Houston with the existing software modified. A web-based user interface is under development to provide a public access for generating reports from the model outputs and measurement data. The key system components are described below.

Figure 1. Sketch map of the air quality information infrastructure. 
sor, Emissions Processing System version 2 (EPS2), and a regulatory model for Texas, the Comprehensive Air Quality Model with Extensions (CAMx) (Environ, 2000) in this framework to facilitate comparative evaluation of different modeling systems. MetProc in Figure 1 transforms the MM5 output to provide meteorological data for CAMx. CMAQ and CAMx differ in many science areas such as in their dynamics descriptions, vertical and horizontal grid structures, detailed physics and numerical algorithms used. Such differences are bound to produce different air quality simulation results. A powerful method for improving our understanding of the atmospheric processes involved with air quality problems is the comparative evaluation of results gained from different modeling systems when compared against available observations, such as the TexAQS 2000 experiment data. Together with the various input databases and analysis tools described below, the combination of multiple meteorological, emissions, and air quality modeling tools and associated processors form a powerful information infrastructure that allows processing of measurement and modeled air quality data.

\section{Databases and Analysis Tools}

To complete the information infrastructure, a variety of environmental datasets are compiled and prepared. Some of the input data are already provided for in certain modeling systems. However, for most cases, the users have to supplement additional necessary input datasets for meeting their spatial and temporal requirements. Table 1 describes the essential datasets required for the meteorological modeling, processing emissions, and air quality simulations, respectively. Among these, the USGS landuse data is available as a part of the MM5 modeling system. The data can be downloaded from the website; (ftp://ftp.ucar.edu/mesouser/MM5V3/TERRAIN DATA). EPA's 1996 National Emissions Trend (NET 1996) and the 1999 National Emissions Inventory (NEI 1999) can be obtained from the website; (ftp://ftp.epa.gov/pub/ EmisInventory/). TCEQ's 2000 emissions inventory data are available from the website (http://www.tnrcc.state.tx.us/air/aqp/ airquality_photomod.html\#ei) in the CAMx-ready data format. Some of the base inventory data is also available from TCEQ. The GEOS-CHEM global chemistry data is provided by Harvard University. Road link node and vehicle-mileage traveled (VMT) data for HGA have been obtained through the Houston-Galveston Area Council (HGAC) and the Texas Transport Institute (TTI).

To characterize the meteorological conditions and to compare air quality model simulations, we have compiled a set of meteorological and air quality data. Table 2 summarizes the measurement data available for August and September 2000 for HGA in the TexAQS 2000 experiment period. Most of these data are classified into the air quality data (both surface and airborne) and meteorology data (surface, buoy, airborne, radar, satellite data as well as weather analysis charts provided by UNISYS).

The measurement data and model simulation output are analyzed with several different analysis tools. In addition to the general statistical and mathematical tools such as SAS ${ }^{\circledR}$ and MATLAB $^{\circledR}$, we have implemented Vis5D (used

Table 1. Input Databases Used for Meteorological Modeling, Emissions Processing, and Air Quality Simulations

\begin{tabular}{|c|c|c|}
\hline Data & Description & Category \\
\hline EDAS & $\begin{array}{l}\text { NCEP Eta model on the Eta212 (AWIP } 40 \mathrm{~km} \text { ) analysis } \\
\text { data used for the initialization of MM5 }\end{array}$ & Meteorology \\
\hline USGS Landuse data & Landuse data needed for MM5 & Meteorology \\
\hline TexAQS biogenics vegetation data & $\begin{array}{l}\text { Updated Texas landuse/vegetation data for biogenic } \\
\text { emissions processing. }\end{array}$ & Emissions \\
\hline EPA NET 1996 & National Emissions Trend inventory for year 1996 & Emissions \\
\hline EPA NEI 1999 & National Emissions Inventory for year 1999 & Emissions \\
\hline $\begin{array}{l}\text { TCEQ } 2000 \text { Texas emissions } \\
\text { inventory }\end{array}$ & $\begin{array}{l}\text { TCEQ's emissions inventory data for Houston-Galveston } \\
\text { airshed for year 2000. Some of the point source VOC data } \\
\text { are speciated. }\end{array}$ & Emissions \\
\hline GEOS-CHEM output & $\begin{array}{l}\text { Harvard Univ. and NASA's GEOS-CHEM } 2.5 \text { deg. x } 2.0 \\
\text { deg. global tropospheric chemistry output for summer } \\
\text { 2000. Used as boundary conditions for the continental US } \\
\text { domain CMAQ simulations }\end{array}$ & Air quality \\
\hline US Census Bureau 2000 & $\begin{array}{l}\text { GIS files for Census Bureau } 2000 \text { surrogate data used for } \\
\text { the emissions processing and population exposure study }\end{array}$ & $\begin{array}{l}\text { Emissions, Exposure } \\
\text { study }\end{array}$ \\
\hline $\begin{array}{l}\text { TTI road link node database for } \\
\text { HGA }\end{array}$ & $\begin{array}{l}\text { Texas Transport Institute's data base for the link node and } \\
\text { vehicle mileage traveled for HGA }\end{array}$ & Emissions \\
\hline
\end{tabular}


Table 2. Texas Air Quality Study 2000 Observation Data Compiled at University of Houston

\begin{tabular}{|c|c|c|c|}
\hline Category & Data & Variables list & Data Period \\
\hline \multirow[t]{3}{*}{ Aircraft } & $\begin{array}{l}\mathrm{NCAR}^{*} / \mathrm{NO} \\
\mathrm{AA}^{*} \text { Electra }\end{array}$ & $\begin{array}{l}\mathrm{O}_{3}, \mathrm{CO}, \mathrm{NO}_{\mathrm{y}}, \mathrm{NO}, \mathrm{NO}_{2}, \mathrm{HNO}_{3}, \mathrm{SO}_{2} \text {, air } \\
\text { temperature, dew point, wind speed, wind } \\
\text { direction, altitude, position }\end{array}$ & August $25,27,28,30,2000$ \\
\hline & $\mathrm{DOE}^{*} \mathrm{G} 1$ & $\begin{array}{l}\mathrm{O}_{3}, \mathrm{CO}, \mathrm{NO}_{\mathrm{y}}, \mathrm{NO}, \mathrm{NO}_{2}, \mathrm{HNO}_{2}, \mathrm{HNO}_{3}, \mathrm{PAN}, \\
\mathrm{SO}_{2} \text {, VOCs, aerosol, air temperature, dew point, } \\
\text { wind components (u-, v-, w-), altitude, position, } \\
\text { air speed, UV radiation, short and long wave } \\
\text { radiation }\end{array}$ & $\begin{array}{l}\text { A total of } 18 \text { flights between } \\
\text { August } 19 \text {-September } 12,2000\end{array}$ \\
\hline & $\begin{array}{l}\text { Baylor }^{*} \\
\text { TCEQ }^{*} \\
\text { Twin Otter }\end{array}$ & $\begin{array}{l}\mathrm{O}_{3}, \mathrm{SO}_{2}, \mathrm{CO}, \mathrm{NO}_{\mathrm{y}}, \mathrm{NO}, \mathrm{NO}_{2} \text {, total nitrates, } \\
\text { VOCs, aerosol, air temperature, dew point, } \\
\text { wind components (u-, v-, w-), altitude, latitude } \\
\text { \& longitude, wind direction, wind speed, air } \\
\text { temperature, dew point, relative humidity }\end{array}$ & $\begin{array}{l}\text { August } 10,16,18,19,21,22,24, \\
25,26,28,29,30, \text { September } 1,3 \\
4,5,7,12,15,2000\end{array}$ \\
\hline \multirow{4}{*}{$\begin{array}{l}\text { Surface and near- } \\
\text { surface chemistry } \\
\text { data }\end{array}$} & AIRS $^{*}$ & $\mathrm{CO}, \mathrm{NO}, \mathrm{NO}_{2}, \mathrm{NO}_{\mathrm{x}}, \mathrm{O}_{3}$ & August 20-September 2, 2000 \\
\hline & $\begin{array}{l}\text { TCEQ } \\
\text { CAMS }\end{array}$ & $\mathrm{CO}, \mathrm{NO}, \mathrm{NO}_{2}, \mathrm{O}_{3}$ & August 20-September 3, 2000 \\
\hline & La Porte & $\begin{array}{l}\text { ALD2, CO, ETH, HCHO, ISOP, NO, } \mathrm{NO}_{2}, \\
\mathrm{NO}_{\mathrm{y}}, \mathrm{O}_{3}, \text { OLE, PAN, PAR, } \mathrm{SO}_{2}, \mathrm{TOL}, \mathrm{XYL}\end{array}$ & August 20-September 2, 2000 \\
\hline & $\begin{array}{l}\text { Williams } \\
\text { Tower }\end{array}$ & $\begin{array}{l}\mathrm{CO}, \mathrm{HCHO}, \mathrm{HNO}_{3}, \mathrm{HONO}, \mathrm{NO}, \mathrm{NO}_{2}, \mathrm{NO}_{\mathrm{y}}, \\
\mathrm{NO}_{z}, \mathrm{O}_{3}, \mathrm{PAN}, \mathrm{SO}_{2}\end{array}$ & August 20-September 2, 2000 \\
\hline \multirow[t]{2}{*}{ NOAA buoy data } & $\mathrm{NDBC}^{*}$ & $\begin{array}{l}\text { air and sea surface temperatures, dew point, } \\
\text { pressure, wind speed, wind direction, pressure } \\
\text { tendency }\end{array}$ & January 1-December 31, 2000 \\
\hline & PORTS $^{*}$ & wind speed, wind direction, pressure & August 1-September 30, 2000 \\
\hline $\begin{array}{l}\text { Surface meteoro- } \\
\text { logy }\end{array}$ & $\begin{array}{l}\text { TCEQ } \\
\text { CAMS }\end{array}$ & $\begin{array}{l}\text { wind speed, wind direction, temperature, } \\
\text { relative humidity, solar radiation, pressure, } \\
\text { precipitation }\end{array}$ & August 20-September 3, 2000 \\
\hline \multirow[t]{3}{*}{ PBL height } & $\begin{array}{l}\text { NOAA } \\
\text { ETL }^{*} \\
\text { airborne } \\
\text { lidar }\end{array}$ & PBL depth & $\begin{array}{l}\text { August 25, 26, 28, 29, 30, 31, } \\
\text { September 1, } 2000\end{array}$ \\
\hline & radiosonde & $\begin{array}{l}\text { PBL depth at Houston SW, La Marque, and } \\
\text { Wharton sites }\end{array}$ & August 23-September 1, 2000 \\
\hline & $\begin{array}{l}\text { wind } \\
\text { profiler }\end{array}$ & $\begin{array}{l}\text { PBL depth at Houston SW, Ellington, Liberty, } \\
\text { La Marque, and Wharton sites }\end{array}$ & $\begin{array}{l}\text { August 25, 26, 28, 29, 30, 31, } \\
\text { September 1, } 2000\end{array}$ \\
\hline \multirow[t]{2}{*}{ Radar } & $\mathrm{HGA}^{*}$ & radar image over HGA & August 16-September 19, 2000 \\
\hline & Texas & radar image over Texas & August 15-September 19, 2000 \\
\hline \multirow[t]{2}{*}{ Satellite } & Texas & satellite (GOES*) image over Texas & August 15-September 19, 2000 \\
\hline & US & satellite (GOES) image over US & August 1-September 31, 2000 \\
\hline \multirow{5}{*}{$\begin{array}{l}\text { Wind Profiler } \\
\text { (ASCII data and } \\
\text { image files) }\end{array}$} & Wharton & wind, virtual temp & August 28-September 15, 2000 \\
\hline & $\begin{array}{l}\text { Houston } \\
\text { SW }\end{array}$ & wind, virtual temp & August 16-September 15, 2000 \\
\hline & Liberty & wind, virtual temp & August 16-September 15, 2000 \\
\hline & Ellington & wind, virtual temp & August 18-September 15, 2000 \\
\hline & La Marque & wind, virtual temp & September 5-September 15, 2000 \\
\hline
\end{tabular}

*Acronyms used in the table are defined in the Appendix A.

extensively for the volume rendering of the meteorological and air quality data, http://www.ssec.wisc.edu/ billh/ vis5d.html), PAVE (a customized public domain visualization system developed for the EPA's CMAQ system with addi- tional capability allowing input of CAMx data), EPA's visualization tools (a set of specially designed codes for visualization of CMAQ and aircraft measurement data) based on Data Explorer (OpenDX, http://www.research.ibm.com/ 
$\mathrm{dx} /$ ), and customized routines to allow visualization of air quality model inputs and outputs with the Geographical Information System (GIS). The GrADS tools and the NCAR Graphics System provide many specialized visualization options for the meteorological data.

\section{Application of Modeling Tools and Databases for the Houston Galveston Airshed Ozone Nonattainment Problems}

To demonstrate the use of the air quality modeling and analysis infrastructure, several air quality simulations and data analyses were performed over the Houston-Galveston area for August 23 - September 1, 2000 (a subset of the TexAQS 2000 period). The experiment period includes three high ozone spikes; August 25, 30, and 31. We have used the MM5 mesoscale meteorology model, SMOKE and EPS2 emissions processing systems, EPA's CMAQ and Environ's CAMx air quality models for the simulations.

\subsection{Evaluation of MM5 simulations for the August 23- September 1, 2000 episode}

Nielsen-Gammon $(2001,2002)$ at Texas A\&M University (TAMU) provides base case MM5 simulation (hereafter TAMU MM5) results for the TexAQS 2000 episode. For the simulations, he specified a set of soil moisture availability values for different land-use categories to represent precipitation and evaporation events prior to the August 22-29, 2000 period and to reflect the dry and hot conditions during the August 30-September 2 period. The one-way nested simulations with the 43 vertical levels in the atmosphere for the $36-\mathrm{km}, 12-\mathrm{km}$, and 4-km resolution domains centered for the Houston-Galveston area were made. The modeling options used are; lower-tropospheric layer nudging of water vapor, a counter-gradient planetary boundary layer mixing scheme (so called MRF scheme), and the slab soil model option. In the base case simulation, the initially higher soil moisture availability value in August 22 was decreased during the model integration replicating evaporation of rain that fell just prior to the ozone episode. A new subroutine was added to MM5 to allow the MM5 model to incorporate the updated soil moisture. The base case model runs are expected to produce generally accurate daytime lower tropospheric temperatures and winds. For most days of the episode, the meteorological fields appear to be adequate for driving the particular combination of mixing and chemical processes that lead to high ozone on each of those days (Nielsen-Gammon, 2002).

While the simulations provide relatively reliable meteorological characterizations, the daily maximum boundary layer heights simulated by TAMU MM5 are about 30\% higher than those estimated from the wind profiler observations. Therefore, a comparative evaluation was performed based on MM5 outputs using a recent NOAH land-surface model (N:National Center for Environmental Prediction; O: Oregon State University; A: Air Force; H: Hydrological Research Lab.) (Ek et al., 2001) to see if the results have been improved as compared to the previous one. UH's alternative 4-km grid meteorological simulations were compared with the driver MM5 simulations using hourly meteorological observa- tions from TCEQ surface sites for the period of August 22 September 1, 2000.

Table 3. Performance Benchmarks of MM5 Simulation for Wind and Temperature Proposed by Emery et al. (2001)

\begin{tabular}{ll}
\hline Component & Bench marking value \\
\hline \hline Wind speed Total RMSE & $2.0 \mathrm{~m} / \mathrm{s}$ \\
\hline \hline Wind Speed Index of Agreement & 0.6 \\
$(\mathrm{IOA})$ & 20 degrees \\
\hline \hline Wind Direction Gross Error & $\pm 0.5 \mathrm{~K}$ \\
\hline \hline Temperature Bias & $2.0 \mathrm{~K}$ \\
\hline \hline Temperature Gross Error & 0.7 \\
\hline \hline Temperature Index of Agreement \\
(IOA)
\end{tabular}

A quantitative evaluation of meteorological simulations was undertaken using the METSTAT statistics analysis package (Emery et al., 2001). METSTAT computes a set of statistical quantities, including bias, gross error, RMSE (Root Mean Square Error, total, systematic, and unsystematic), and index of agreement for winds, temperatures, and humidity. The Index Of Agreement (IOA) is a measure of the match between the departure of each prediction from the observed mean and the departure of each observation from the observed mean. Thus, the correspondence between predicted and observed values across the domain at a given time may be quantified in a single metric and displayed as a time series. The index of agreement has a theoretical range of 0 to 1 , where 1 suggests perfect agreement (Emery et al., 2001). Table 3 shows the values for wind and temperature. We used these benchmarks to investigate the performance of both MM5 simulations in wind field.

\section{$\underline{\text { MM5 Wind Statistics }}$}

The hourly performances of TAMU MM5 and UH MM5 simulations for wind speed and wind direction were compared with the 23 surface meteorological measurement sites available in the modeling domain. In general, the time series analysis for wind direction demonstrates both model simulations produce results close to the observations. However, a relatively larger discrepancy between observed and predicted wind speed is shown in the TAMU simulation run during the morning period on August 25. Unlike the TAMU base MM5 simulations, the UH MM5 simulation had trouble reproducing the rapid transition of wind direction in the morning of August 25.

Figures $2 \mathrm{a}$ and $2 \mathrm{~b}$ provide average statistics for wind directions and speeds demonstrating differences between the TAMU and UH MM5 simulations. The IOA for wind speed indicates that the TAMU MM5 simulations show slightly better agreement with observations than the UH MM5 simulation. 

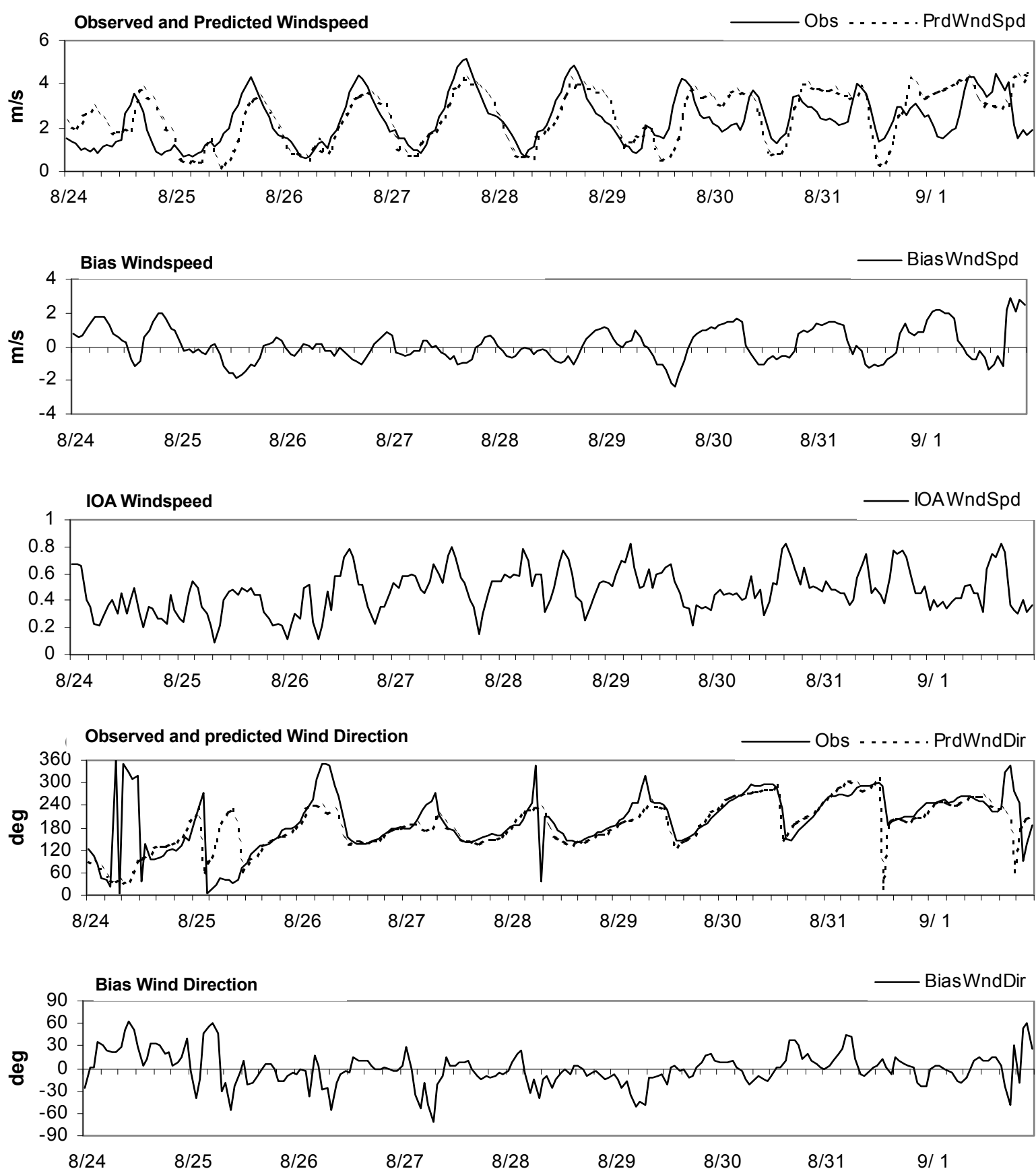

Note: IOA represents the index of agreement.

Figure 2a. Domain averaged hourly surface wind statistics for 4-km TAMU MM5 run. 

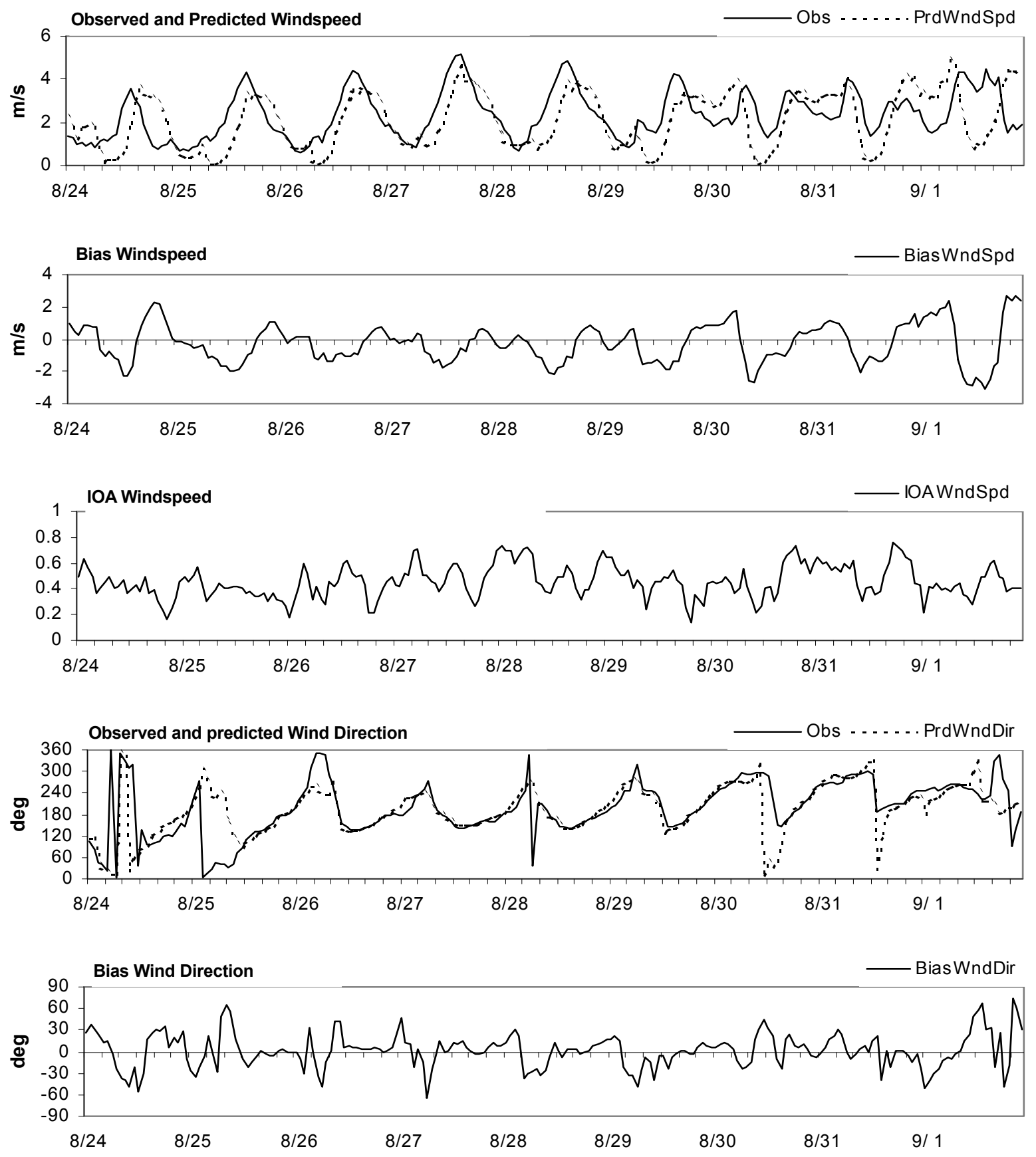

Figure 2b. Domain averaged hourly surface wind statistics for 4-km University of Houston MM5 run. 


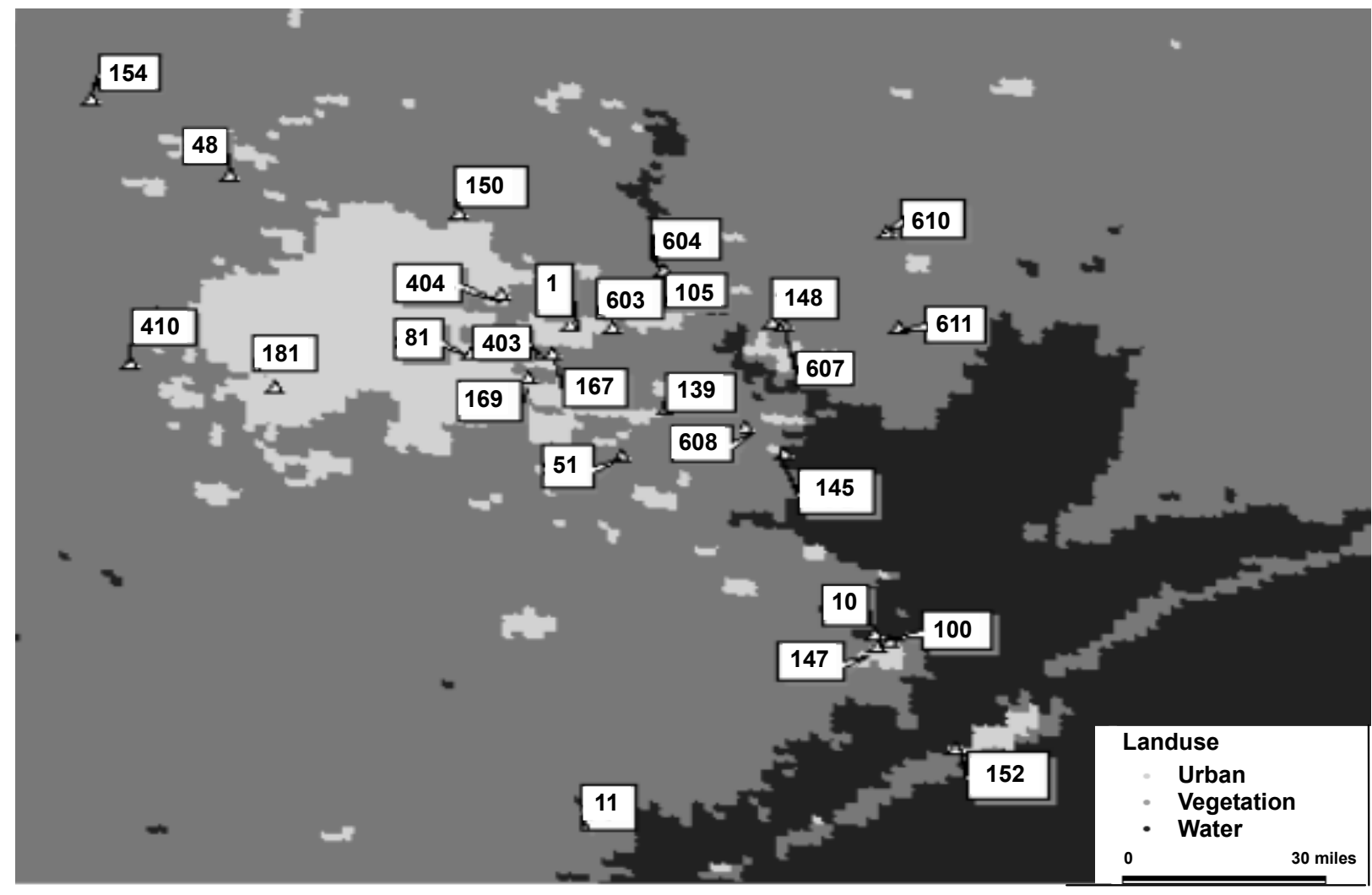

Note: The location of each site is represented with a triangle symbol and the corresponding site number is provided inside the rectangle.

Figure 3. CAMS measurement sites and simplified landuse categories.

UH MM5 simulation shows around 2 hours time lag in wind speed. The wind speed bias is no more than $3 \mathrm{~m} / \mathrm{s}$ in both MM5 simulations. The wind direction bias is consistently smaller than that of wind speed. The IOA for wind speed is typically 0.5 , and thus both MM5 simulations satisfied the MM5 performance requirement proposed by Emery, et al. (2001).

\section{MM5 Temperature Statistics}

The CAMS measurement sites are used to evaluate the 2-m temperature simulation results with observations (Figure 3 ). The background color shows different land use types and one can see most of the CAMS sites are located in the rural areas. Domain averaged 2-m temperatures of measurement and the MM5 simulation are shown in Figure 4. Plate (a) is for urban sites and plate (b) is for rural sites. For the urban sites, both simulations show consistent temporal evolution patterns. UH MM5 simulation improves the maximum temperature predictions while showing serious nighttime temperature low bias (around 2 degrees) in both urban and rural areas. At the present time, we suspect that the systematic bias is caused by heat capacity and emissivity values associated with the dominant land-use categories used in the simulation.

\section{Planetary Boundary Layer Heights}

The regime of active atmospheric turbulence near the earth's surface is called the planetary boundary layer (PBL). The PBL height is a key parameter that determines the extent of the dispersion of pollutants. Like many other atmospheric turbulence parameters, the PBL height can vary greatly over different landuse, vegetation surfaces and over the sea. Here we have compared the simulated PBL heights with those estimated from the wind profiler data for La Marque (LM), Ellington (EL), Houston SW (HS), Wharton (WH), and Liberty (LB) profiler sites, and radiosonde data from La Marque, Houston-Galveston (HG), and Wharton. The locations of profiler sites are shown in Figure 5. The background color shows the different land use types, and one can see all the profiler sites are located in the rural areas surrounding Houston. In Figures 6a, and b, August 27 and August 30 were selected to study the patterns of PBL height development. The simulation from TAMU has higher PBL height prediction than profiler data especially on August 30. The PBL height prediction from UH MM5 simulation shows a consistent distribution with profiler data. However, both simulations failed to capture the low PBL height at the LM site. The inland WH site shows 
the highest PBL height values on August $27^{\text {th }}$. In the afternoon, the decrease of PBL heights for the sites near the coast demonstrates the influence of the sea breeze. In general, the TAMU MM5 simulations show much higher and rapid growth of the PBL heights while the UH simulations show better agreements with observed PBL heights.

\subsection{Emissions processing for the Houston-Galveston area}

There are significant differences between the national and state emissions inventories. A detailed evaluation of the differences is only possible when both of the emissions inventories are processed through different emissions process- ing systems used by different organizations. Since this study requires going through different processing steps based on different data formats, comparative work of this kind has been rare. An attempt to compare different inventories and emissions processing systems can be found in Kim and Byun (2003).

Table 4 compares national and state emissions inventories (EI) for HGA. National and state EI based on the U.S. EPA's NEI 1999 final version 2 (ftp://ftp.epa.gov/ EmisInventory/finalnei99ver2/) and TCEQ's TexQAS2000 emission inventory (ftp://www.tnrcc.state.tx.us/pub/OEPAA/ TAD/ Modeling/ HGAQSE/Modeling/EI/; TCEQ, 2002). As shown in
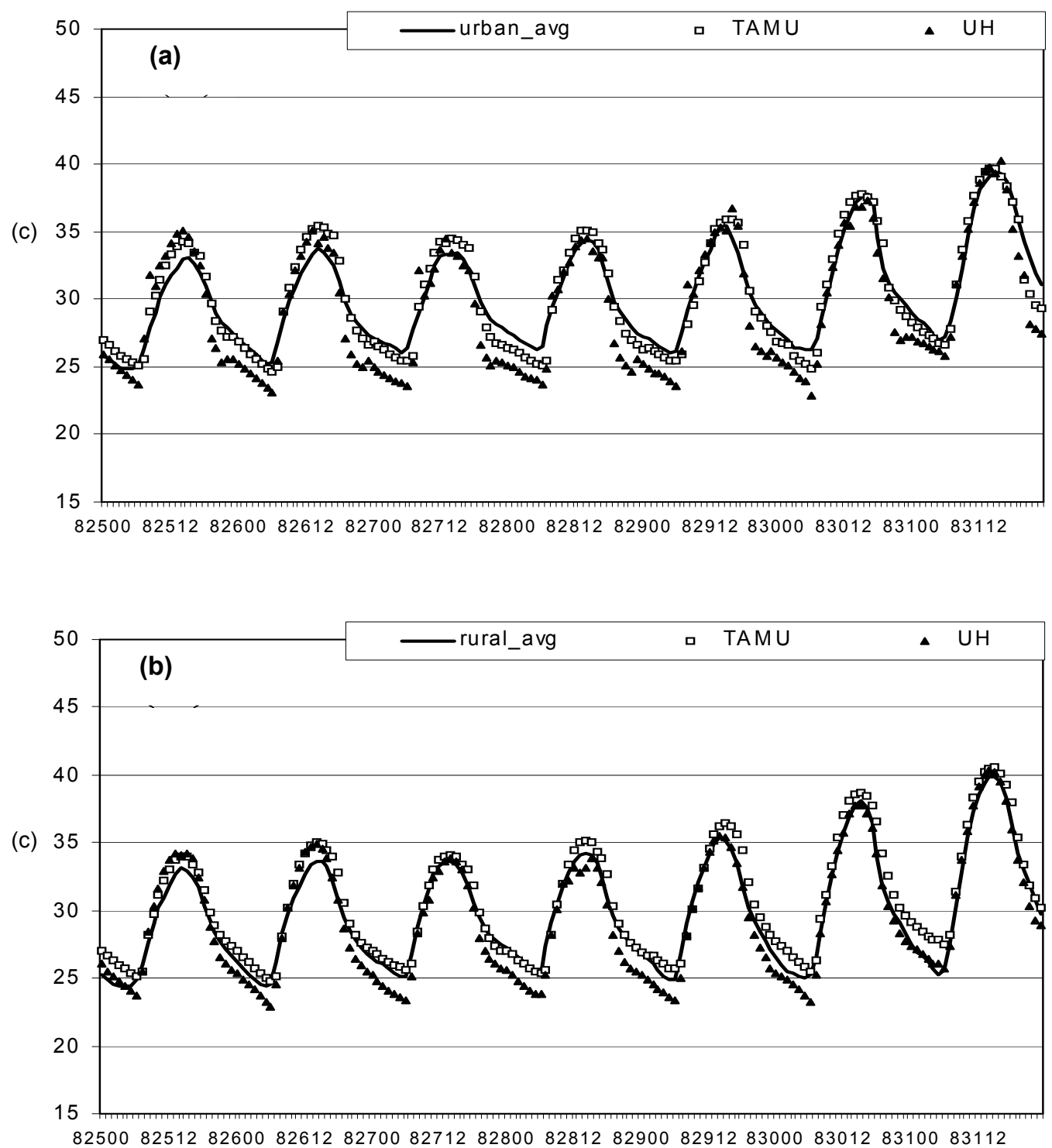

Figure 4. Simulated and observed time series of 2-m air temperatures at (a) urban and (b) rural sites. 


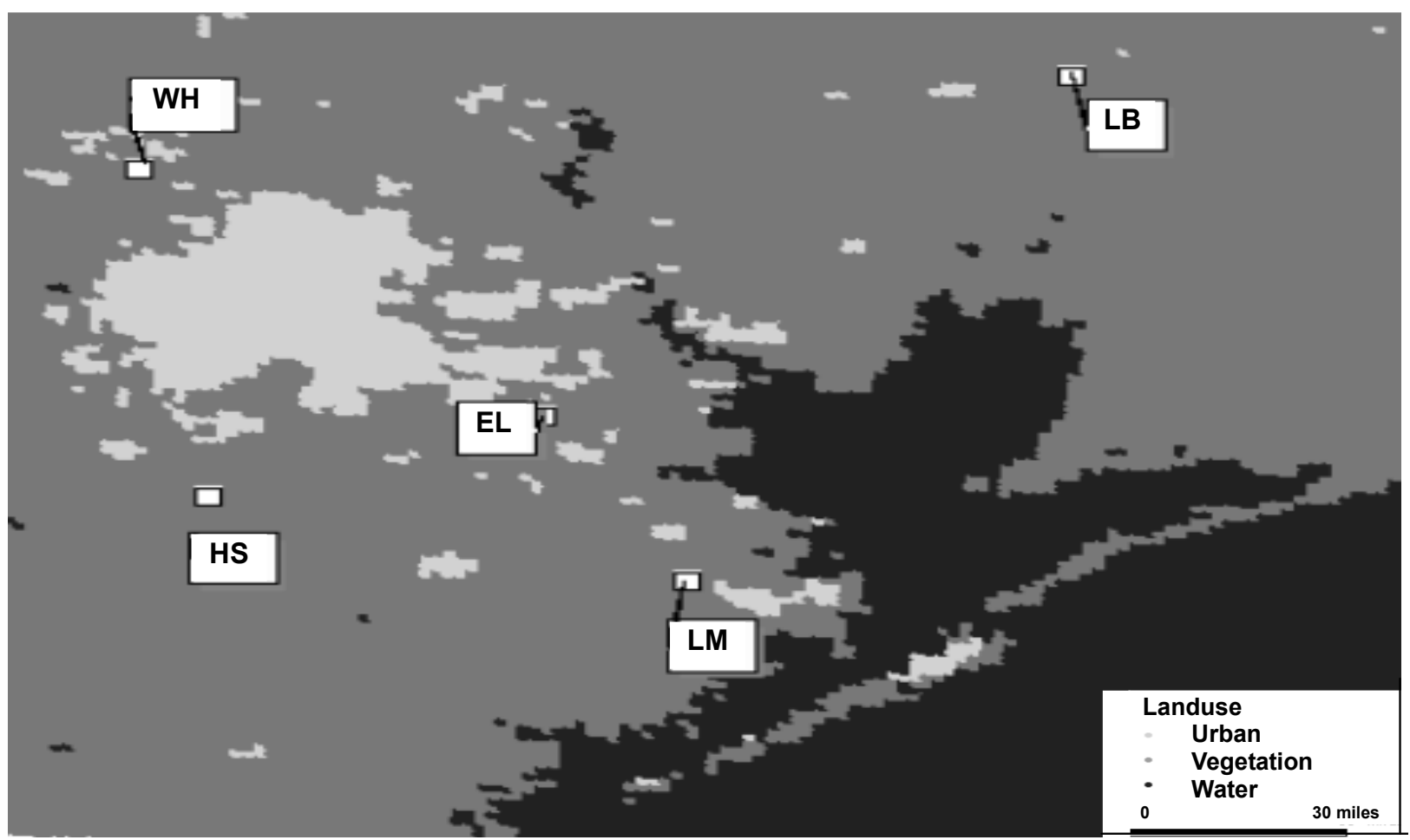

Note: La Marque (LM), Ellington (EL), Houston SW (HS), Wharton (WH), and Liberty (LB) sites are sown in the figure.

Figure 5. Wind profiler sites used to evaluate planetary boundary layer height evaluation.

Table 4, there are significant differences between the national and state emissions inventories.

Processing of National Emissions Inventory (NEI) with SMOKE

EPA recommends the use of the SMOKE Tool (Benjey et al., 2001) as the emissions processor for the CMAQ modeling system. The SMOKE Tool is used to generate the necessary inputs for SMOKE for the grid allocation processing, such as to define the grid, to compute fractional coverage of spatial features in relation to model grid, and to generate spatial surrogate files to allocate emissions data. The SMOKE Tool is coded in the SAS ${ }^{\circledR}$ and Arc/Info ${ }^{\circledR}$, and has been configured to operate from the Models3 Study Planner and to provide input files in the required formats to the SMOKE system. However, the implementation and operation of the Models-3 framework requires expensive third party software and experienced operators. In addition, there are substantial recurring costs associated with installing $\mathrm{SAS}^{\circledR}$ and $\mathrm{Arc} / \mathrm{Info}^{\circledR}$ on a UNIX workstation. Therefore, we have installed the SMOKE Tool on a Windows PC without using the Models-3 framework.

Table 4. NOx and VOC Emissions for HGA 8-county Area in National and State Emissions Inventories

\begin{tabular}{lcccc}
\hline \multirow{2}{*}{ Source type } & \multicolumn{2}{c}{ NOx (tons/day) } & \multicolumn{2}{c}{ NOC (tons/day) } \\
\cline { 2 - 5 } & National & State & National & State \\
\hline On-road mobile & 353 & 246 & 255 & 156 \\
Area / Nonroad mobile & 192 & 193 & 227 & 241 \\
Point & 521 & 490 & 152 & 327 \\
8-County total anthropogenic & & & & \\
emissions & 1066 & 929 & 633 & 724 \\
\hline
\end{tabular}


TAMU_Aug. 27 PBL ht(m)

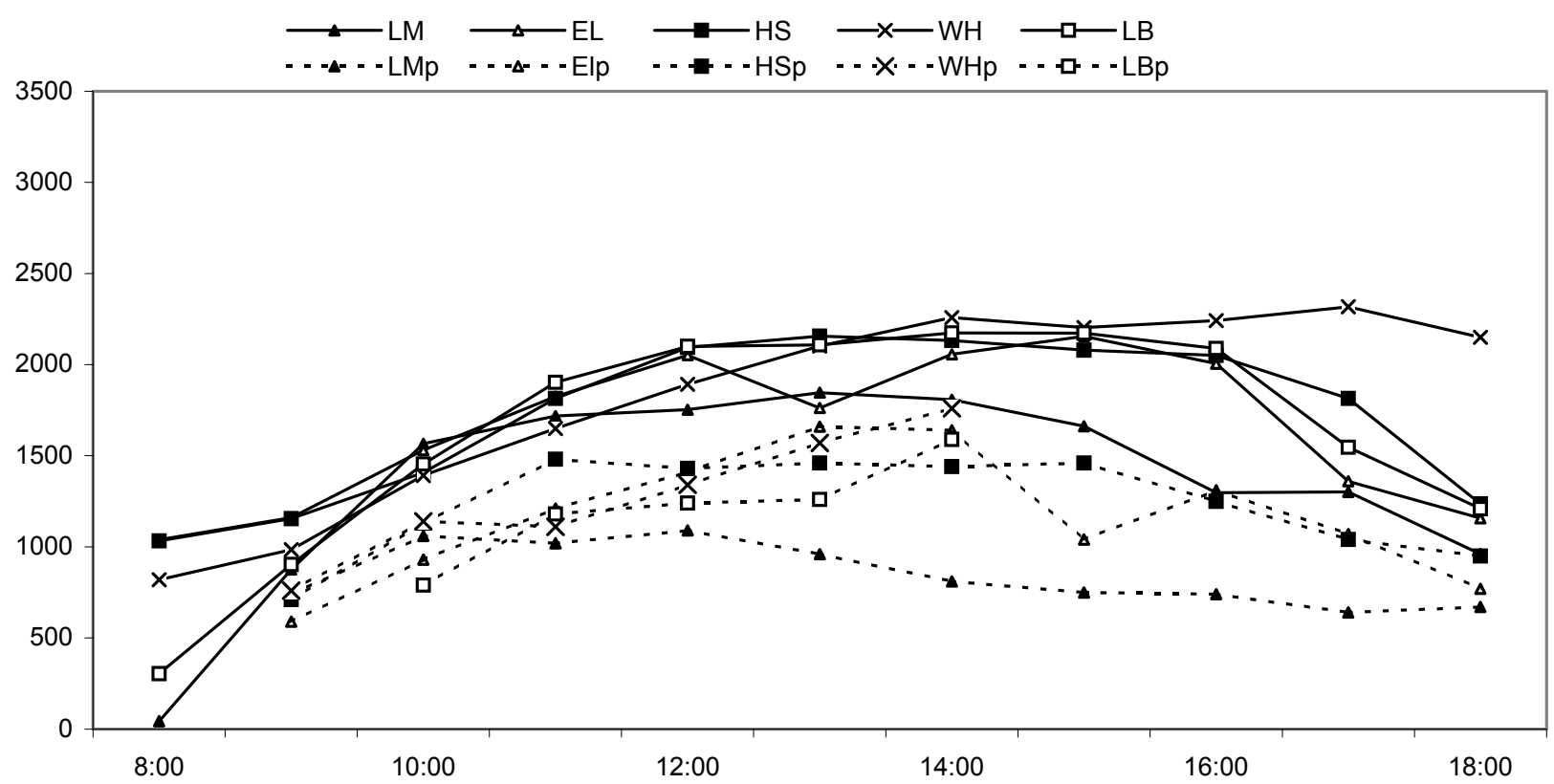

UH_NOAH_Aug. 27 PBL ht(m)

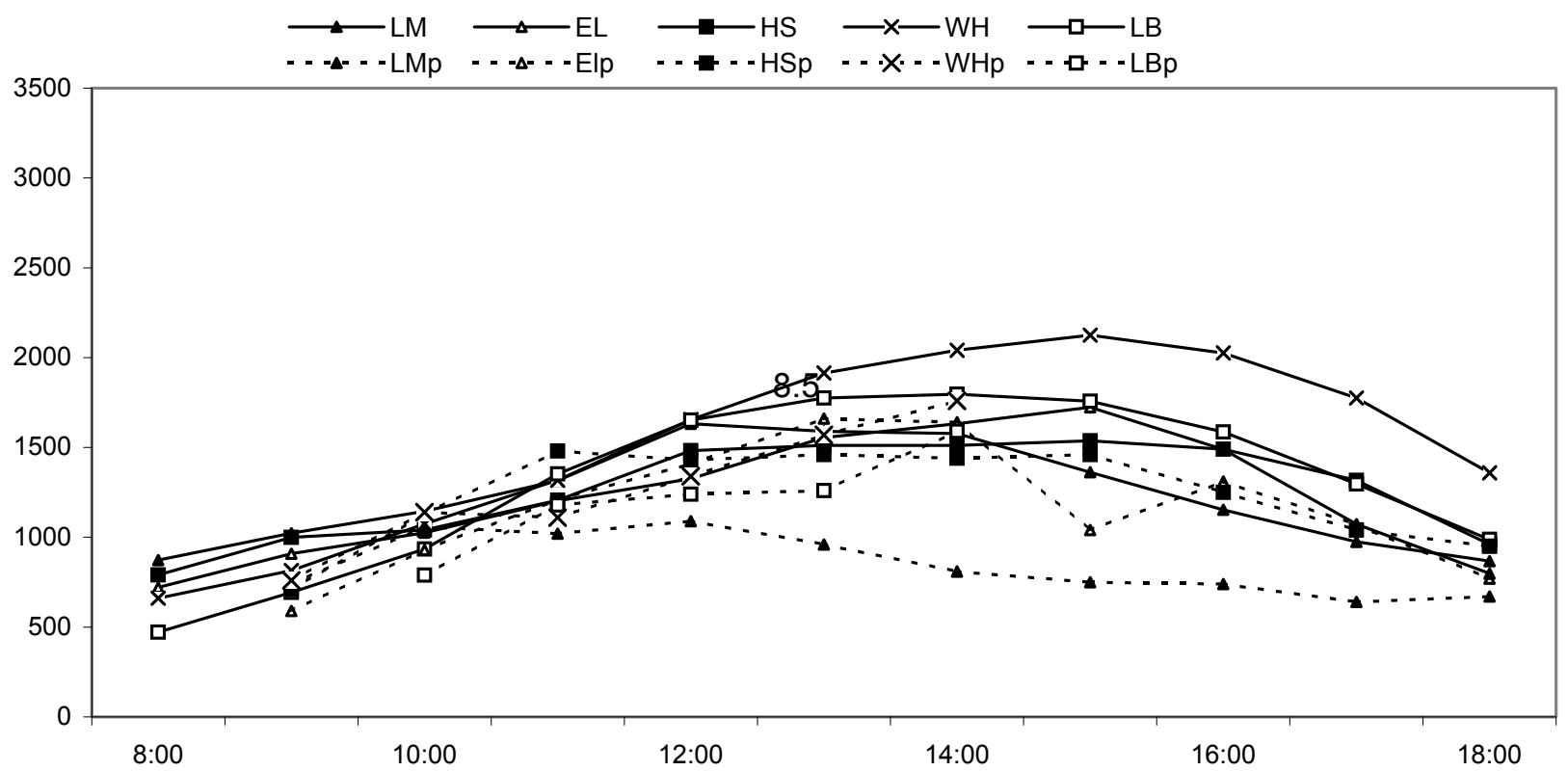

Note: Solid line is from MM5 simulation; dotted line is wind profiler data.

Figure 6a. Comparison of the PBL height development from TAMU and UH MM5 simulations and wind profiler data on August 27, 2000. 

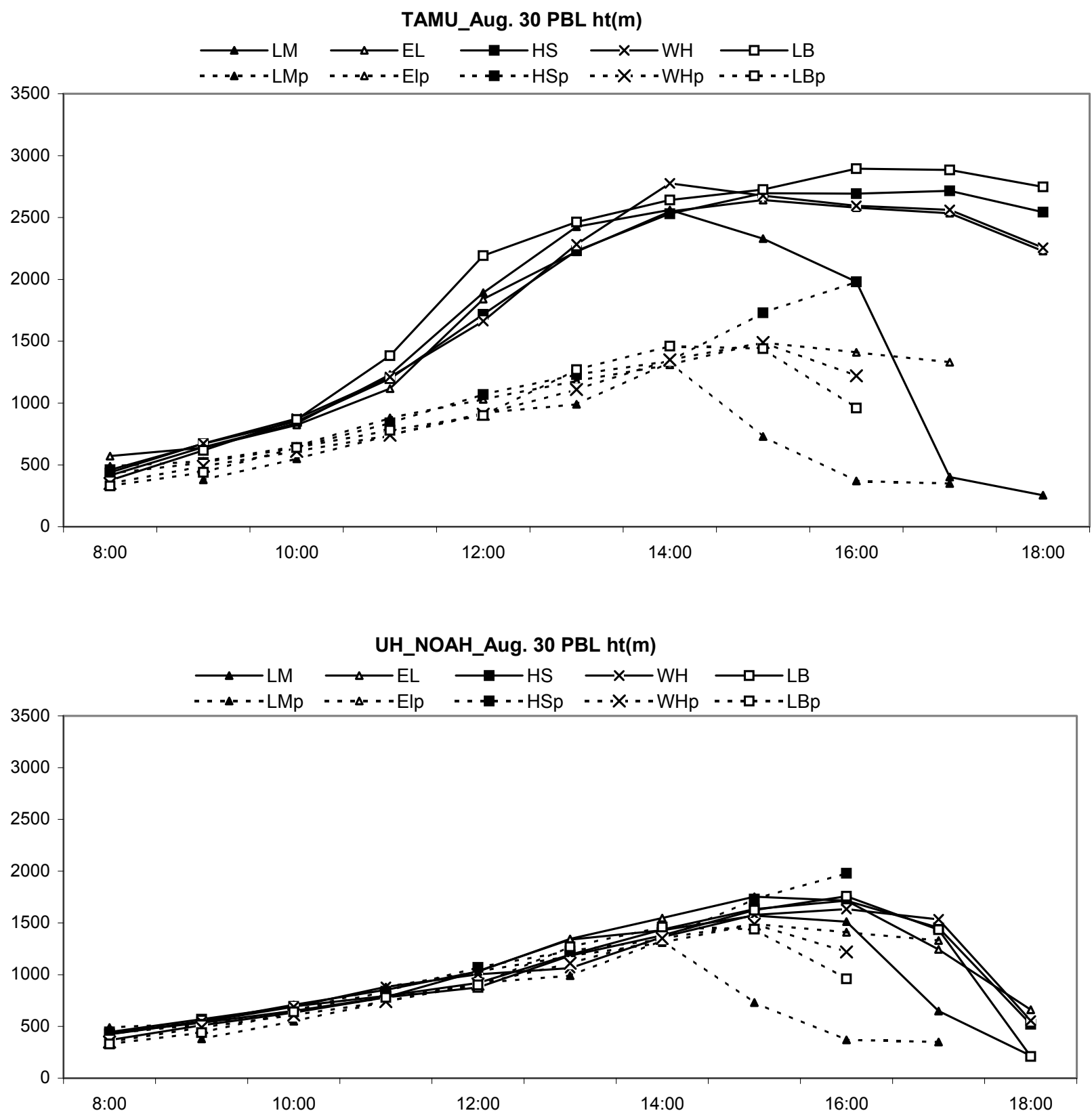

Note: Solid line is from MM5 simulation; dotted line is wind profiler data.

Figure 6b. Comparison of the PBL height development from TAMU and UH MM5 simulations and wind profiler data on August 30, 2000. 
Recently the Multimedia Integrated Modeling System (MIMS) Spatial Allocator has been developed (sponsored by the EPA) to provide a tool for generating spatial surrogates for emissions and to perform other types of spatial allocation without requiring a GIS or SAS (Eyth and Hanisak, 2003). However, many of the MIMS components have not yet been compared with to functions provided by the SMOKE Tool.

SMOKE has been used for studying the episode of $\mathrm{Au}$ gust 23, 2000-September 1, 2000, using the 36-, 12- and 4-km grid domains for area, mobile, point and biogenic sources. The input data includes the use of the NET96 IDA inventory provided by the EPA for point, area mobile emissions and BEIS2 (Pierce et al., 1998) for biogenic emissions in both SMOKE-CB4 and SAPRC99 chemical mechanisms. The more recent version of NEI99 data, which was released in March 2003, is yet to be quality assured and is not available in the correct data format that can be processed with SMOKE or EPS2. Output data for all sources has been generated in the form of hourly, gridded, chemically speciated emissions in the units of moles/s. For area emissions, SMOKE converts inventory pollutants to hourly and gridded emissions of the chemical species data. As for mobile emissions, emissions data from the NET96 mobile source inventory was directly used. For biogenic emissions processing, both county-based vegetation data and Biogenic Emissions Land-use Data (BELD) (Kinnee et al., 1997) gridded data converted for the map projection were used for Texas simulations. In the case of point source processing, the inventory pollutants were converted to the hourly and gridded emissions of the chemical mechanism species. The "layer fraction method" was used to calculate plume rise.

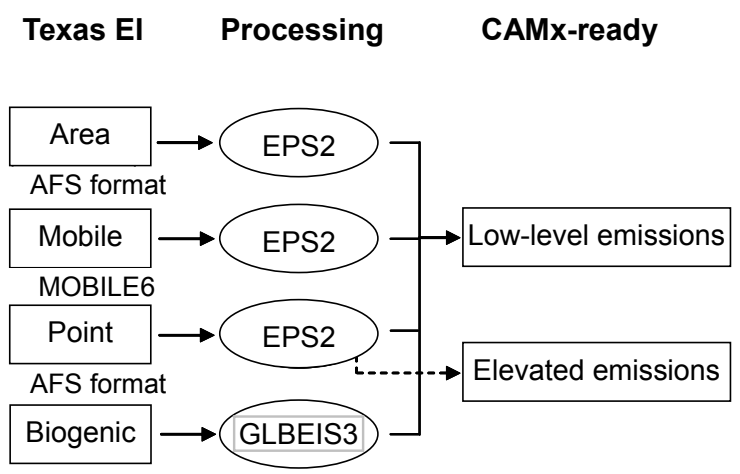

Figure 7. Processing of Texas emissions inventory with EPS2.

Processing of Texas Emissions Inventory (TEI) with $\underline{\text { EPS2 }}$

EPS2 (Emissions Preprocessor System version 2) was chosen to process TCEQ's Texas emissions inventory data. Area and nonroad mobile source (AMS) emissions were imported using the PREAM (PREprocessor for Area and Mobile sources) module and then processed for chemical speciation, temporal and spatial allocation using TCEQ-prepared cross-reference and profile files specified for Texas emissions inventory (Funk et al., 2001; TNRCC, 2002). The emission inventory for on-road mobile sources includes link-based MOBILE6 outputs for the 8 counties around the HGA. Prior to importing the emissions into LBASE (Link-BASEd emissions processor), FORTRAN code replacing the UNIX-SAS program was used to convert the file format from MOBILE6 to LBASE, and to adjust vehicle and emission types for further processing. PREPNT (PREprocessor for PoiNT source emissions) was used to import point source data in AIRS Facility Subsystem (AFS) format. Because the processing of point source emissions produces a CAMx-ready file for the low level sources and an ASCII file for the elevated major sources according to stack parameters such as stack height, exhausting gas temperature, and velocity, the elevated source file was processed additionally before use (U.S. EPA, 1992). In the case of biogenic emissions, GLOBEIS3 (http:// www.globeis.com/) results were processed by TCEQ using radiation estimated by satellite data analysis and observed temperatures. Since the emissions inventory for each source type was prepared in more detailed categories and processed separately, the merging process was required to integrate the low level emissions as shown in Figure 7.

Conversion of CAMx-ready Texas Emissions Data for CMAQ simulations

EPS2 cannot generate model-ready emissions data for CMAQ. To process the TCEQ emissions inventory with the SMOKE system, changes in the data files used for EPS2 and adaptation of a few EPS2 modules are needed. To utilize the TCEQ's emissions data for CMAQ simulations, we have developed alternative steps to convert CAMx- ready emissions for CMAQ. This is necessary because the EPA NET96 is too old to represent reality in the year 2000 . Although projection of the data in 2000 is possible, it would be less reliable. Thus, TCEQ has invested significant resources to generate the most up-to-date emissions data for the TexAQS 2000 period. The method allows us to use more realistic emissions data in the simulations and provides an opportunity for comparing CMAQ results for a large number of emissions sensitivity cases, from NET96 IDA to current TCEQ emissions data. However, the CAMx-ready emissions data is only available for the CB-IV mechanism and at $12-\mathrm{km}$ and $4-\mathrm{km}$ resolutions. The overall processing steps are summarized in Figure 8. To convert CAMx-ready emission data into CMAQ input data, we set up the processing steps such as unit conversion, species renaming and coordinate conversion. For both area and point sources, it is necessary to read the CAMx-ready emission in binary data format, rename the species, and convert the units accordingly to CMAQ needs. As for point sources, additional work is required to rearrange a set of point sources, such as major stack parameters and major emissions, and the MEPSE stack parameters and MEPSE emissions, which will be treated through the plume-in-grid process. These inputs are processed with the Emission-Chemistry Interface Processor (ECIP) to generate CMAQ-ready emissions data (as seen in Figure 1). 
CAMx Emissions Data Processing for CMAQ

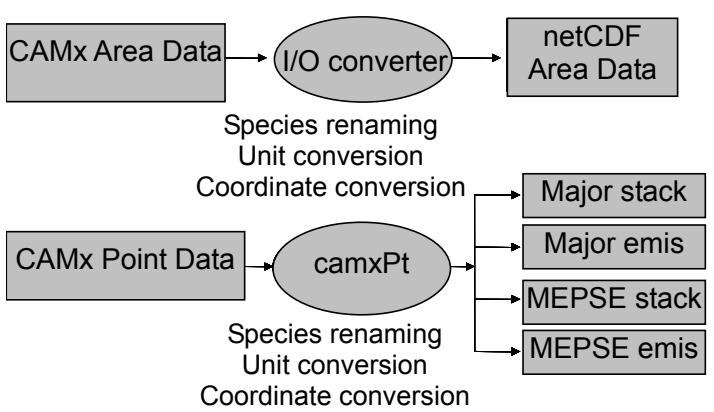

Note: Stacks with large emissions are divided into major sources that are distributed into the multiple model layers through the plume-rise process and the major elevated point source emissions (MEPSE) that are treated as Lagrangian plumes (i.e., using the plume-in-grid module) until the plume size becomes large enough to be dumped into the Eulerian grid.

Figure 8. Conversion of CAMx-ready emissions data to generate input for CMAQ.

\subsection{Simulations of TexasAQS 2000 ozone events with EPA's CMAQ model}

The TexAQS 2000 episode had numerous exceedences (i.e., daily maximum ozone concentration greater than 125 ppb) in both Houston and Beaumont. There were six exceedence days in the HGA during the eight-day period, including a period of low ozone in the middle. The episode includes 5 days with the veering flows (wind vectors turning clockwise direction) that are associated with flow reversal and high ozone. Light easterly winds resulted in a maximum ozone concentration at Crawford near the center of the Houston area on August 25 and southeasterly winds carried the maximum level of ozone out of Houston to Conroe (about 40 miles north of Houston) on August 26. August 27 and 28 were the two low ozone days, with stronger southeasterly sea breeze winds resulting in substantially lower ozone in the HGA by transporting the diluted urban plume to Conroe. August 29, 30, and 31 showed light westerly morning winds followed by afternoon sea breezes which put the ozone pool on the east side of the city at Mt. Belvieu, La Porte and Deer Park, reflecting the maximum value in that area (refer to Figure 9). A relatively persistent westerly land breeze carried the maximum level of ozone to the Baytown monitor and points further east on September 1st.

It is worthwhile to simulate the episode with CMAQ using the two different chemical mechanisms; the Carbon Bond IV (CB-IV) mechanism (Gery et al., 1988; 1989) and SAPRC-99 mechanism (Carter, 1990, 2000a,b). The Carbon Bond mechanism is a lumped structure mechanism where organics are divided into smaller elements based on the types of carbon bonds in each species. For example, single bonded carbon atoms, regardless of the molecule in which they appear, are represented using a one-carbon atom alkane surrogate called PAR, and carbon-carbon double bonds are represented using a two-carbon atom surrogate denoted as OLE. Thus, in the CB-IV formulation, a molecule such as propylene, which contains one alkyl group and one carbon-carbon double bond group, is represented as $1 \mathrm{PAR}$ and 1 OLE. A species such as n-pentane, which contains five alkyl groups, is represented as 5 PAR. Ethylene and isoprene are treated explicitly.

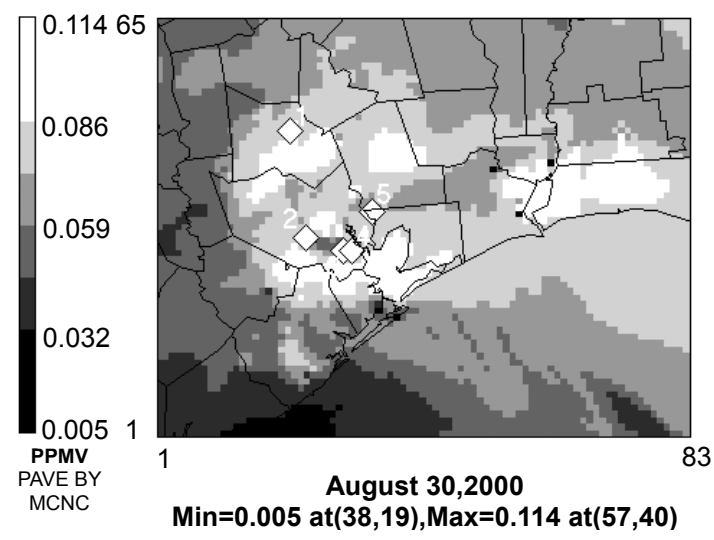

Note: . The diamond symbols represent the observed daily maximum ozone concentrations at Conroe (1), Crawford (2), Deer Park (3), La Porte (4) and Mt. Belvieu (5). The simulation misses the peak measured ozone concentrations during the day.

Figure 9. Simulated daily maximum surface ozone concentration for August 30, 2000.

The SAPRC-99 is a lumped molecule mechanism, where a particular organic compound or a generalized species is used to represent similar organics (based on the reactivity of species). More species are treated explicitly in this approach. The propylene molecule is represented as a part of OLE1, which is a group of primary alkenes. Internal alkenes are grouped into the OLE2 surrogate.

Because of large olefin emissions from Houston Ship Channel area, we need to have a good representation of olefins. Ethylene is treated explicitly in both mechanisms. However, propylene and butadiene, both highly photo- chemically reactive species, are grouped with other hydrocarbons and their reaction rates and molecular masses are averaged in a group. Therefore one of our future research projects is to explicitly represent propylene and butadiene in a modified SAPRC mechanism to answer the question of whether the condensed chemical mechanisms can predict the rapid ozone formation observed in HGA.

To differentiate the effects of using different mechanisms in the CMAQ simulations, emissions for CB-IV and SAPRC-99 mechanisms prepared by the SMOKE system consistent with the 1996 NET inventory were used. Since the most up-to-date 2000 Texas inventory is available only for the CB-IV mechanism, it is not possible to utilize this inventory for such comparison. CMAQ simulations showed that the highest episode maximum ozone concentration associated with these two mechanisms is $136 \mathrm{ppb}$ for CB-IV and $156 \mathrm{ppb}$ 
for SAPRC-99, respectively, which is closer to the TCEQ's Chemistry Air Monitoring Site (CAMS) observations in the area. The overall ozone distributions are similar and the highest maximum ozone concentration occurs at the same time (hour 20:00 UTC on August 31, 2000). The simulations with the SMOKE-processed NET96 emissions data showed up to $30 \mathrm{ppb}$ differences between the CB-IV and SAPRC mechanisms in the Ship Channel areas (Figure 10a). Areas of large difference are found near the downwind side of the Houston Ship Channel area where significant olefin emissions exist (see Figure 10b). Some of TexAQS NOAA aircraft measurements support these findings. This demonstrates that SAPRC-99 is better than the CB-IV in terms of the realization of high reactivity of the olefin species. Figure 11 shows that the SAPRC mechanism predicts higher (about 15\%) ozone concentration from the mid to upper concentration range. This result is consistent with the results of the work such as, Dodge (2000) and Harley et al. (1997).

(a)
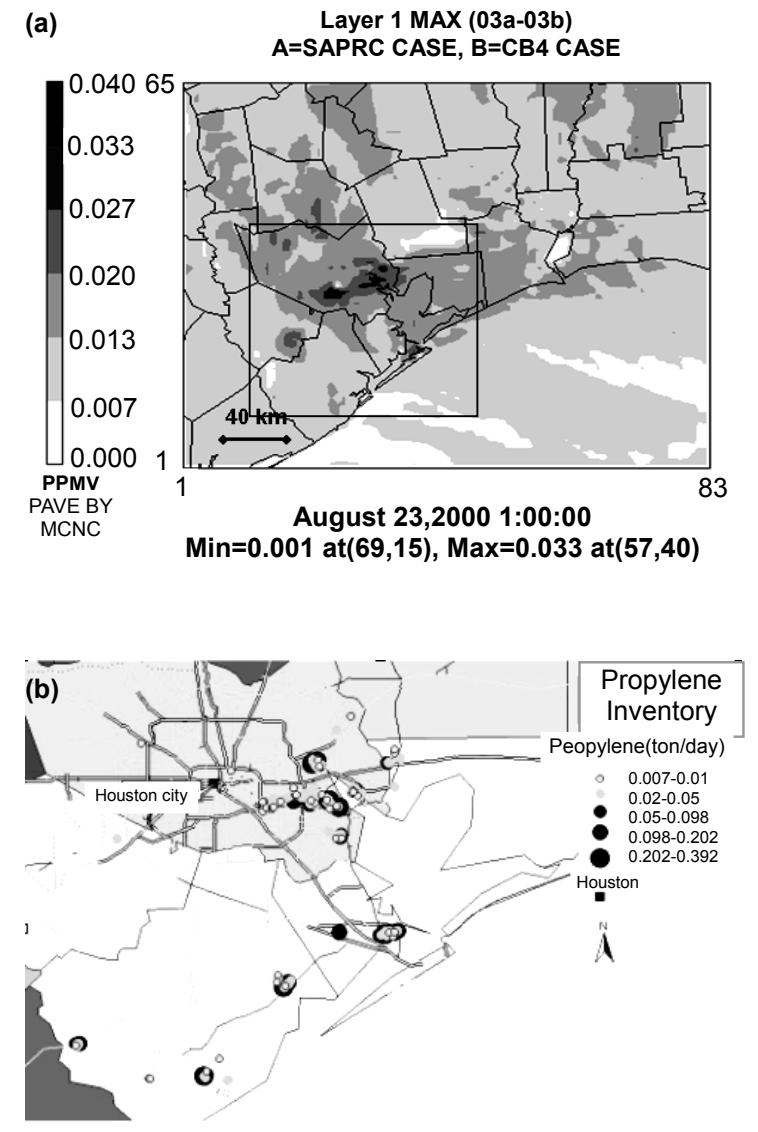

Figure 10. (a) Daily maximum ozone concentration differences (SAPRC99 result minus CB-IV), and (b) locations of large propylene emissions sources in HGA.

Accuracy of the emissions data used in the simulation is always of great concern for modeling studies. Two major emissions inventories (NET96 and Texas 2000) are compared in Figure 12. CMAQ CB-IV simulation results with the Texas inventory improve the simulation with much smaller scatter than those with the NET96 (least square values from 0.708 to 0.765 in Figure 13 (a) and (b)) and there is obvious change in the slope representing larger under-prediction of higher ozone concentrations. These results correspond with other analyses of the TexAQS 2000 experiment that state the current Texas inventory needs improvement, in particular VOC emissions from point sources and $\mathrm{NO}_{\mathrm{x}}$ and $\mathrm{CO}$ emissions from mobile emissions (e.g., refer to Accelerated Science Evaluation of Ozone Formation in the Houston-Galveston Area available from http://www.utexas.edu/research/ceer/ texaqsarchive/pdfs /EXEC_SUMMARY_Nov_02.pdf).

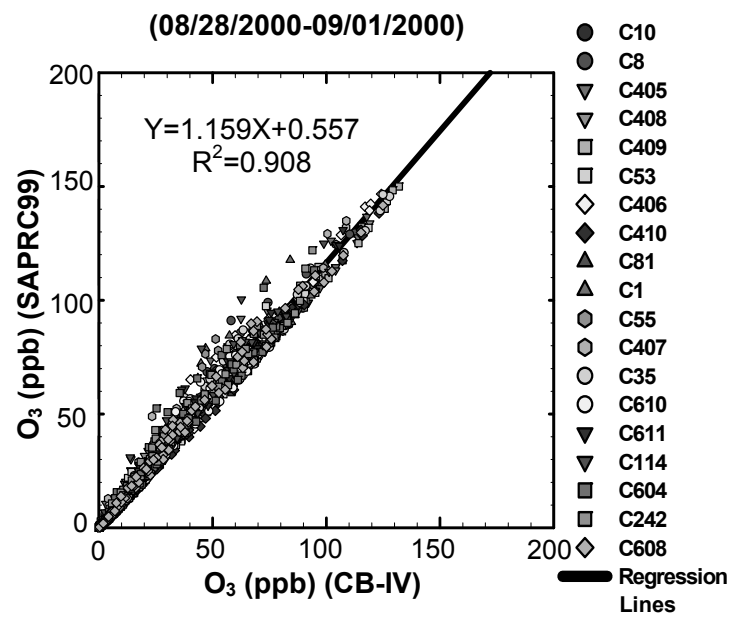

Figure 11. Comparison of CMAQ SAPRC and CB-IV mechanism simulations.

\subsection{Testing emissions scenarios with CAMx}

The researchers at the UH Institute for Multidimensional Air Quality Studies (IMAQS) work with the Task Force for Ozone Reduction Strategies (TFORS) to provide sensitivity tests on the local air quality models. TFORS brings together interested stakeholders (business, environmental nongovernmental organizations, medical professionals, academics and regulatory personnel) with the best science for the purpose of recommending the best policy solutions to solve the Houston-Galveston area ozone problem. The TFORS group has suggested several scenarios to run, and thus far UH IMAQS has run two scenarios. The first one called for a $20 \%$ reduction in Vehicle Miles Traveled (VMT). Taking the emissions from Mobile6 and making 20\% across the board reductions in emissions established the emissions profile for this scenario. (This is a close approximation to reducing the VMT of each type of vehicle on the road by $20 \%$ ). The second scenario called for a doubling of the number of SUV's on the road. This analysis actually kept the total VMT constant (due to constraints of Mobile6) by reducing the number of passenger vehicles by the amount of SUV's that were increased. The 
emissions for both scenarios were processed and run in CAMx for the period from August 21 to September 1, 2000. CAMx, the current TCEQ's SIP regulatory model, was used for this test and we reviewed the results focusing on the high ozone days of August 25, 29, 30 and 31 .

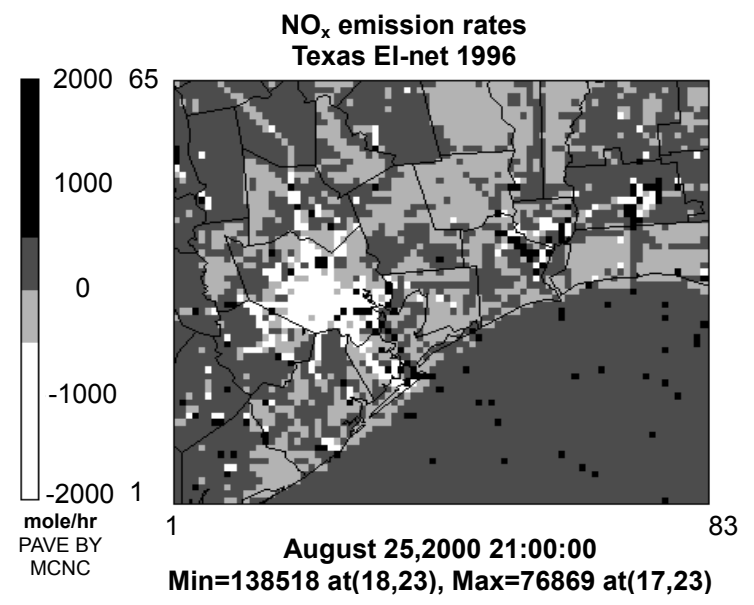

Figure 12. Comparison of NOx emission rates in Texas EI and NET 1996. The difference was calculated by subtracting NOx emission rates in NET 1996 from those in Texas EI.

Details of the model validation process and the files used to run the model are available at the following sites:

- http://www.tnrcc.state.tx.us/air/aqp/airquality techcom.ht

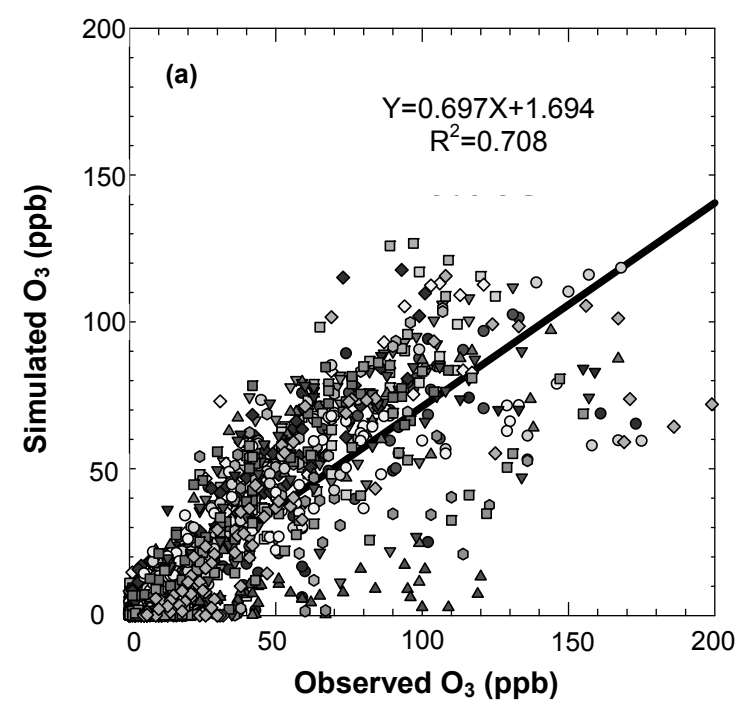

ml\#section5

(PMTC Meeting Notes and Presentations in PDF format:)

- $\mathrm{ftp} / / / \mathrm{ftp}$.tnrcc.state.tx.us/pub/OEPAA/TAD/Modeling/HG AQSE/Sci Tech_Committees/PMTC/20030319/Houston Ozone Model Update_20030319-JimSmith.pdf

- $\mathrm{ftp} / / / \mathrm{ftp}$. tnrcc.state.tx.us/pub/OEPAA/TAD/Modeling/HG AQSE/Sci_Tech_Committees/PMTC/20020619/Olefin NOx_Eequivalence_2000Episode_JimSmith.pdf

- $\mathrm{ftp} / / / \mathrm{ftp}$. tnrcc.state.tx.us/pub/OEPAA/TAD/Modeling/HG AQSE/Sci Tech Committees/PMTC/20020918/TCEQ Regulatory_Modeling_JimSmith.pdf

For the 20\% VMT reduction case we observed approximately a $20 \%$ reduction in mobile emissions of NO. Reductions in other chemical emissions showed similar results. When compared with the overall NO emissions (Figure 14), the reduction is very small (about $6 \%$ ). Because mobile emissions show relatively higher emission rates for NOx $(246$ tons/day) than VOC's (156 tons/day) and overall NOx and VOC emissions for HGA are 950 tons/day and 2435 tons/day, respectively (TCEQ, 2002), one would expect that a reduction in mobile emissions would cause an increase in the VOC/NOx ratio as observed in Figure 15.

Before running the scenarios, the base case provided by the Texas Commission for Environmental Quality (TCEQ) was tested. The base case used 2000 emission data without any of the control measures that are stipulated in the State Implementation Plan. The TCEQ made some adjustments to this base case including the increase of highly reactive VOC emissions at point sources so that the ratio of highly reactive VOC's to NOx was equal to 1 .

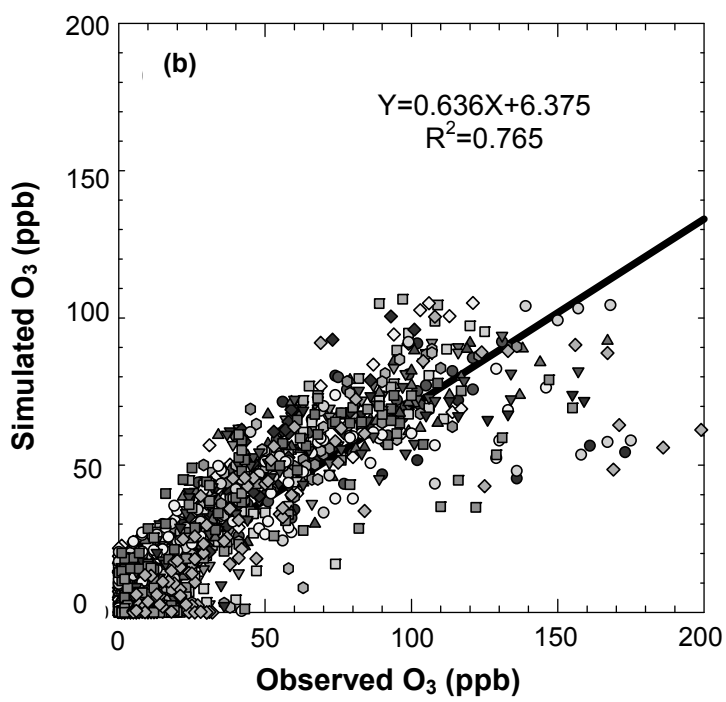

Figure 13. Comparison of CMAQ CB-IV mechanism using (a) 1996 NET and (b) TCEQ 2000 CAMx-ready emissions data (right panel) for all hours of the period of August 28 through August 31, 2000. The thick solid lines represent the linear regression lines. Curve fit results show that the model simulations show serious low bias with the least square values of 0.708 for the NET96 emissions and 0.765 for the TCEQ emissions data. 


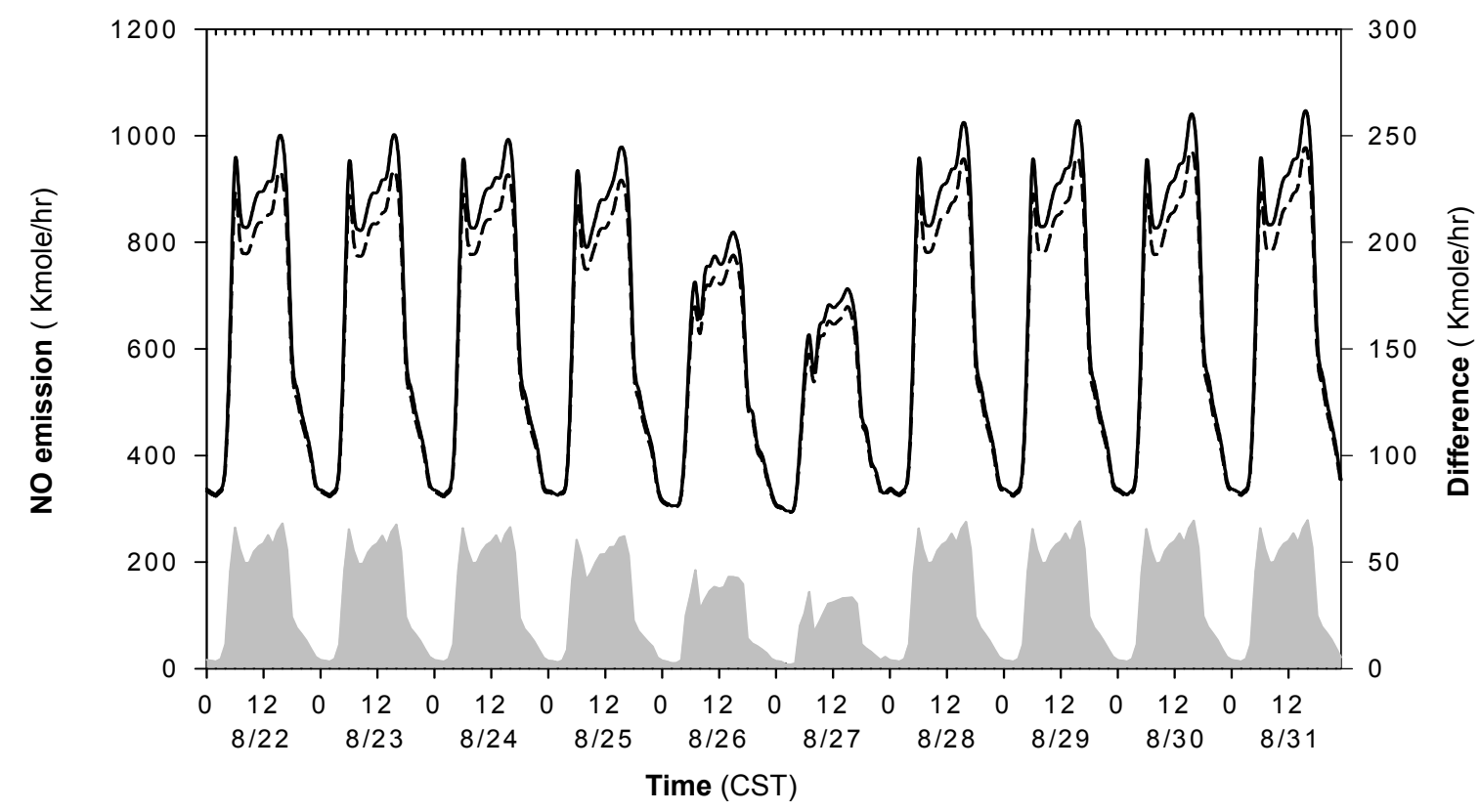

Figure 14. Reduction of VMT by $20 \%$ and its effect on the NO emissions. Although the mobile NO emissions have been reduced by $20 \%$ the reduction results in about $6 \%$ reduction of the total NO emissions. Solid and dashed lines present base and 20\% VMT reduction case, respectively, and area shows NO emission difference in two cases.

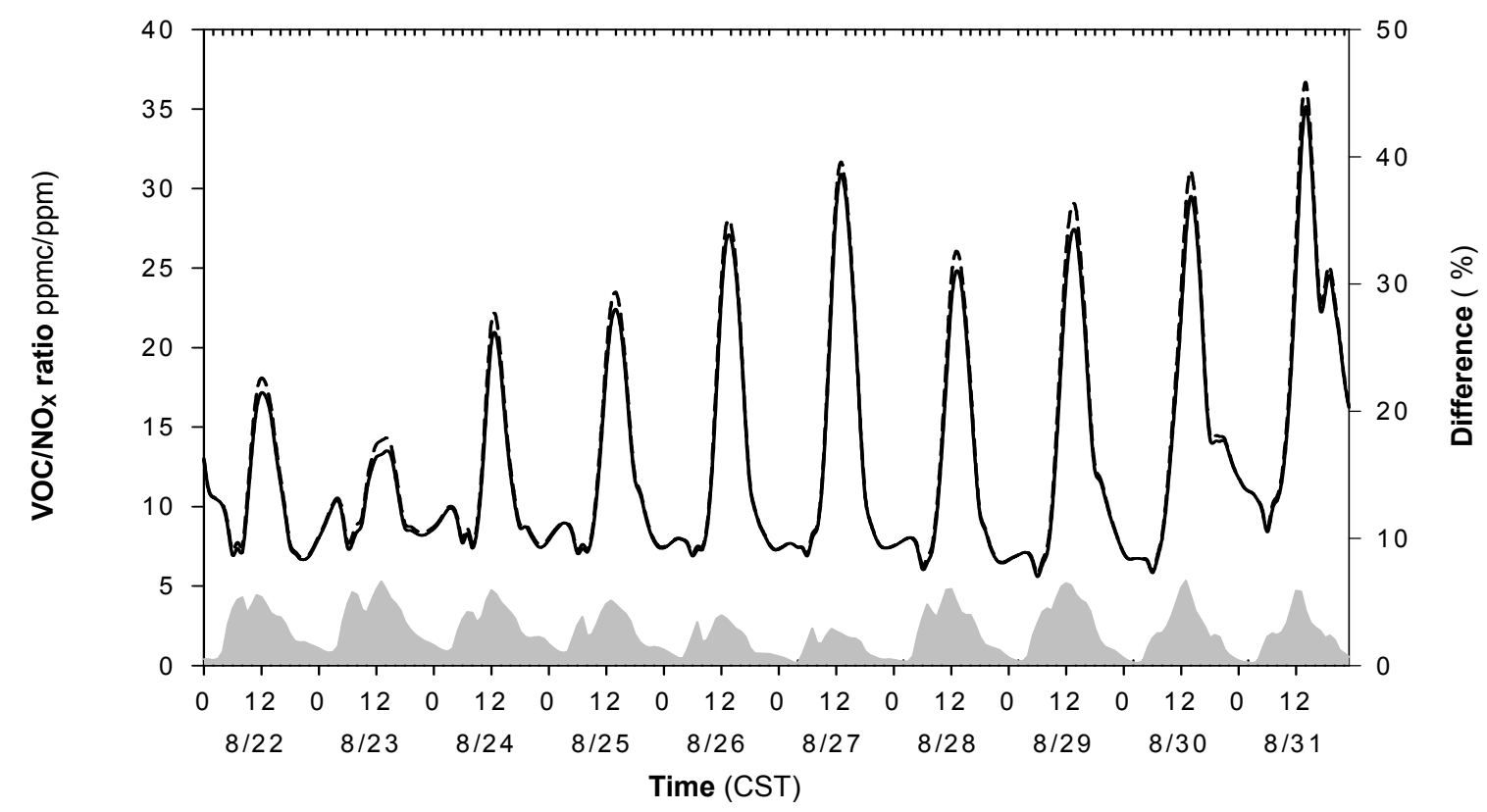

Figure 15. Comparison of VOC/NOx ratio variations between base and 20\% VMT reduction cases. 
(a)

\section{UH_AQM,camx310:20000825,base4a.pt_02n2_070pbl} g=camx310_avrg.20000825.base4a.pt_02n2_070pbl.hgbpa_04km

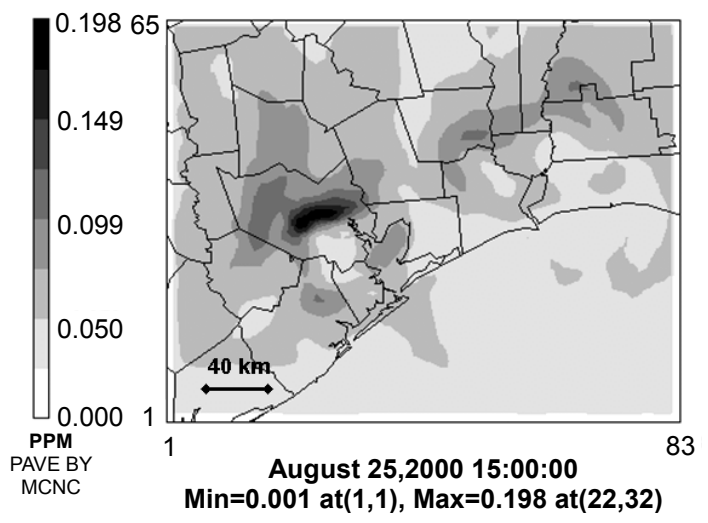

(b)

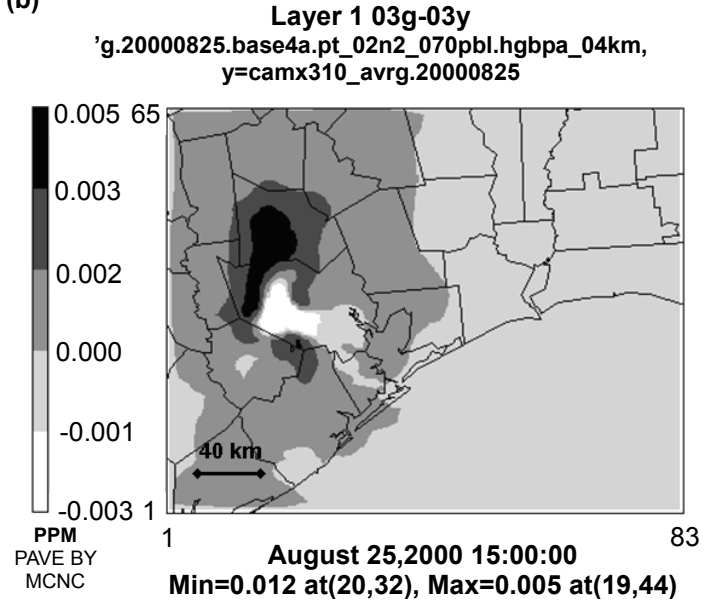

Figure 16. (a) Base case 4-km resolution CAMx simulated ozone concentration and (b) difference in ozone concentrations between the base and 20\% VMT reduction scenario in the eight-counties in HGA for 15 UTC August 25, 2000.

Also, the TCEQ made $30 \%$ reductions in the PBL on all days except for August 30 based on profiler data. These changes were made to the "adjusted base case" so that the model would more accurately reflect the reality based on other data that had been obtained by the TCEQ. The "adjusted base case" was run on the UH sun computer system, and the results were processed and compared with the TCEQ results. In all cases the results obtained matched at levels well within the quality control requirements. Often the largest differences in results were in the $6^{\text {th }}$ or $7^{\text {th }}$ decimal figure.

The results for the $20 \%$ reduction in VMT scenario appeared to be very similar to the adjusted base case result. Figures 16(a) and (b) indicate that reducing the VMT emissions by $20 \%$ will increase ozone concentration in some locations and decrease ozone concentration in other locations. Similar results were observed on August 29 and August 30. Only on August 31 was the base case higher than the VMT 20\% reduction case in ozone concentrations. The fact that ozone increased when VMT emissions were decreased in some locations may simply mean that the $\mathrm{NO}_{\mathrm{x}}$ emissions from vehicles is titrating out the ozone, hence when some of the $\mathrm{NO}_{\mathrm{x}}$ is removed more ozone survives. However, the same results were not found on August 31, which implies there may be some more complex issues involved, such as changing meteorological conditions on different days.

In the sensitivity test in which we doubled the number of SUV's it was found that the changes in emissions were fairly small. In this case doubling the SUV's only increased the carbon monoxide by about $2-3 \%$ on average. The increase in NO was even less, at about $0.3 \%$. The analysis subsequently showed negligible changes in total emissions of $\mathrm{CO}$ and $\mathrm{NO}$, respectively. The fact that the changes in emissions were barely perceptible was also displayed in the adjusted base case when the comparison was made with the doubling of the number of SUV's scenario. There are indeed some differences, however, the scales on the plots indicate that those differences are less than $1 \mathrm{ppb}$, implying that the doubling SUV scenarios shows negligible ozone changes in the HGA. The results of the peak ozone values for the different model runs are summarized in Table 5. The scenario where VMT is reduced by $20 \%$ results in a slight increase in predicted peak ozone on 25th and 30th August due to the reduced NO titration of ozone, but there was a slight reduction in ozone on August 31st demonstrating the response of the regional maximum ozone depends on the meteorological conditions in addition to the VOC/ NOx emissions conditions.

In addition to the "Adjusted Base Case", the TCEQ has also developed the "2007 Control Case" emissions inventory. The 2007 Control Case uses a projected inventory for 2007 using all of the adopted rules in the State Implementation Plan with two exceptions. One is an energy efficiency ("gap measure") and the other is the reduction associated with the permitting of grand-fathered facilities. In both cases there are some difficulties in identifying the amount and location of the emissions reductions. Emissions associated with growth in area, on-road mobile and off-road mobile emissions have been included. No additional emissions were added for point sources since point sources have little or negative growth. Given the control measures, however, the model results show that the Houston-Galveston area will not achieve ozone attainment (Figure 17). The model results for the 2007 Control Case show that for the days of August 25, 29, 30 and 31 the peak ozone values will be 174, 134, 144 and 136 respectively, when the maximum allowable is $125 \mathrm{ppb}$ ozone.

\section{Conclusion}

A research information infrastructure for air quality modeling and data analysis has been built at UH IMAQS. The system includes a set of meteorological models, emissions processing systems, air quality models, a trajectory analysis tool, a GIS-based data analysis/visualization system, and a collection of observational data sets for the HGA housed in a network of computer systems. UH IMAQS plans to help solve the HGA's ozone problems by working with TFORS to develop more scenarios that will identify where the sources of emissions are that must be reduced to reduce ozone. The two 
scenarios run by IMAQS to date did not show dramatic changes in ozone. The scenario that looked at a $20 \%$ reduction in VMT showed mixed results, with some locations increasing in ozone and other decreasing on 3 of the 4 high ozone days. On the fourth ozone day the $20 \%$ reduction in VMT reduced ozone everywhere. The differences are likely due to meteorological conditions, but this must be verified. However, current conditions include high $\mathrm{NO}_{\mathrm{x}}$ and high VOC's. When all control measures are implemented, the changes suggested in the two scenarios presented here will likely increase. This may be tested in future scenarios run on the 2007 Control Case. The scenario that looked at doubling the number of SUV's showed even less change in both emissions and ozone. In fact, the peak ozone values for all four days were identical to the values for the adjusted base case. The change in emissions due to doubling the fleet of SUV's does not appear to have a significant impact under the current conditions. The immediate plans are to run scenarios first removing all mobile source emissions, and next removing just point source emissions. Then emissions will be increased in $25 \%$ increments to identify when the ozone exceedences occur.

The case studies have demonstrated that the infrastructure allows us to perform in-depth analysis of air quality and regulation assessment. In addition to the existing system components described in this paper, future work might be focused on linking the urban/regional air quality models to global scale atmospheric chemistry models, incorporating satellite-based remote sensing air quality data, adding a prototype screening ozone trajectory tool based on a photochemical box model, building an air quality forecasting system composed of a prognostic meteorological model and an air quality mode, and bridging the air quality observations and simulations with the health effects study.

\section{Layer $103 t$}

HDMCR, camx310:20000825, fy07b.pt har37e55altE 070pb $\mathrm{t}=$ camx310_avrg.20000825.fy07b.pt_hat $\mid \mathrm{r} 37$ e55E_070pbl.hg_01

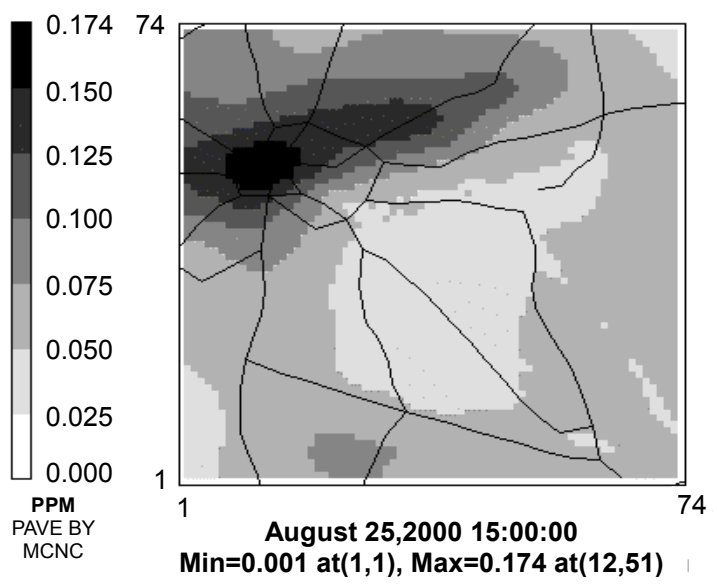

Note: The simulation demonstrates that the currently planned control measure is not sufficient to reduce ozone in HGA below the national ambient air quality standard set at $125 \mathrm{ppb}$.

Figure 17. Simulation of ozone in year 2007 for control case at $1-\mathrm{km}$ resolution.
Table 5. Changes in Ozone Concentrations in HGA for Base, $20 \%$ VMT Reduction, and Doubling of SUV Scenarios

\begin{tabular}{lrrrc}
\hline & Aug. & Aug. & Aug. & Aug. \\
& 25 & 29 & 30 & 31 \\
\hline $\begin{array}{l}\text { Adjusted Base Case } \\
\text { (ppb) }\end{array}$ & 209 & 160 & 161 & 173 \\
$\begin{array}{l}20 \% \text { Reduction of } \\
\text { VMT (ppb) }\end{array}$ & 212 & 159 & 167 & 171 \\
$\begin{array}{l}\text { Doubling SUV (ppb) } \\
\text { DMp }\end{array}$ & 209 & 160 & 161 & 173 \\
\hline
\end{tabular}

Acknowledgments. Although the research described in this article has been funded in part by the United States Environmental Protection Agency through Grants \# R-82906801 and R-83037701 to the University of Houston, it has not been subjected to the Agency's required peer and policy review and therefore does not necessarily reflect the views of the Agency and no official endorsement should be inferred. This work was also funded in part the Texas Air Research Center and their contributions are acknowledged.

\section{References}

Benjey, W.G., Houyoux, M.R. and Susick, J.W. (2001). Implementation of the SMOKE emission data processor and SMOKE tool input data processor in Models-3, in the 10th International Emission Inventory Conference: One Atmosphere, One Inventory, Many Challenges, Denver, CO, USA.

Byun, D.W. and Ching, J.K.S. (1999). Science algorithms of the EPA Models-3 Community Multiscale Air Quality (CMAQ) Modeling System, EPA-600/R-99/030, U.S. EPA.

http://www.epa.gov/asmdnerl/models3/doc/science/science.html.

Carter, W.P.L. (2000a). Documentation of the SAPRC-99 chemical mechanism for VOC reactivity assessment. http://www. cert.ucr.edu/ carter/absts.htm\#saprc99.

Carter, W.P.L. (2000b). Implementation of the SAPRC-99 Chemical Mechanism into the Models-3 Framework. http:/www. cert.ucr.edu/ carter/absts.htm\#s99mod3.

Carter, W.P.L (1990). A detailed mechanism for the gas-phase atmospheric reactions of organic compounds. Atmos. Environ., 24, 481-518.

Coats, C.J.J. and Houyoux, M.R. (1996). Fast emissions modeling with the Sparse Matrix Operator Kernel Emissions Modeling System, in The Emissions Inventory: Key to Planning, Permits, Compliance, and Reporting, Air and Waste Management Association, New Orleans, LA, USA.

Dodge, M.C. (2000). Chemical oxidant mechanisms for air quality modeling: critical review. Atmos. Environ., 34, 2103-2130.

Ek, M., Mitchell, K.E., Koren, V.I., Schaake, J.C., Duan, Q., Lohmann, D., Grunmann, P., Rogers, E., Black, T., Marshall, C., Peters-Lidard, C. and Meyers, T. (2001). Spring 2001 changes to the NCEP Eta Analysis and Forecast System: NOAH land-surface Model, in the 9th Conference on Mesoscale Processes, Fort Lauderdale, FL, USA.

Eyth, A. and Hanisak, K. (2003). The MIMS spatial allocator: a tool for generating emissions surrogates without a geographic information system, in Proc. of the 12th International Emission Inventory Conference, San Diego, CA, USA.

Emery, C., Tai, E. and Yarwood, G. (2001). Enhanced Meteorological 
Modeling and Performance Evaluation for Two Texas Ozone Episodes, Report to the Texas Natural Resource Conservation Commission, College Station, TX, USA.

Environ (2000). Users' Guide for Comprehensive Air Quality Model with Extensions (CAMx): Version 3. www.camx.com/ overview.html.

Funk, T.H., Stiefer, P.S. and Chinkin, L.R. (2001). Development of Gridded Spatial Allocation Factors for The State of Texas, Final Report 3, STI-900570-2114-FR3, Prepared for Texas Natural Resource Conservation Commission, College Station, TX, USA.

Gery, M.W., Whitten, G.Z. and Killus, J.P. (1988). Development and testing of the CBM-IV for urban and regional modeling. http://www.epa.gov/scram001/comments.htm

Gery, M.W., Whitten, G.Z., Killus, J.P. and Dodge, M.C. (1989). A photochemical kinetics mechanism for urban and regional scale computer modeling. J. Geophys. Res., 94, 12925-12956.

Grell, G.A., Dudhia, J. and Stauffer, D.R. (1994). A description of the 5th-generation Penn State/NCAR Mesoscale Model (MM5). NCAR Tech. Note, NCAR/TN-398+STR, 122.

Harley, R.A., Sawyer, R.F. and Milford, J.B. (1997). Updated photochemical modeling for California's South Coast Air Basin: Comparison of chemical mechanisms and motor vehicle emission inventories. Environ. Sci. Technol., 31(10), 2829-2839.

Houyoux, M.R., Vukovich, J.M., Coats, C.J.J., Wheeler, N.W. and Kasibhatla, P.S. (2000). Emission inventory development and processing for the seasonal model for regional air quality (SMRAQ) project. J. Geophys. Res. Atmos., 105(D7), 9079-9090.

Kim, S.T. and Byun, D.W. (2003). Prototyping the Texas emissions inventory preparation system for the SMOKE system, in Proc. of the 12th International Emission Inventory Conference, San Diego, CA, USA.

Kinnee, E., Geron, C. and Pierce, T. (1997). United States land use inventory for estimating ozone precursor emissions. Ecol. Appl., 7, 46-58.
Klemp, J.B., Skamarock, W.C. and Dudhia, J. (2000). Conservative split-explicit time integration methods for the compressible nonhydrostatic equations, Draft Manuscript, WRF Eulerian Prototypr Model Equations Height and Mass Vertical Coordinates, 1-14.

Nielsen-Gammon, J.W. (2001). Initial Modeling of August 2000 Houston-Galveston Ozone Episode, Report to the Technical Analysis Division, Texas Natural Resource Conservation Commission, College Station, TX, USA.

Nielsen-Gammon, J.W. (2002). Meteorological Modeling for the August 2000 Houston-Galveston Ozone Episode: METSTAT Statistical Evaluation and Model Runs from March-June 2002, Report to the Technical Analysis Division, Texas Natural Resource Conservation Commission, College Station, TX, USA.

Pierce, T., Heron, C., Bender, L., Dennis, R., Tennyson, G. and Guenther, A. (1998). The influence of increased isoprene emissions on regional ozone modeling. J. Geophys. Res. Atmos., 103, 25611-25629

Scire, J.S., Robe, F.R., Fernau, M.E. and Yamartino, R.J. (2000). A User's Guide for the CALMET Meteorological Model, Earth Tech., Inc., Concord, MA, USA, pp. 332.

Texas Commission on Environmental Quality (2002). Attachment 3-Emissions Inventory Development and Modeling for the August 25-September 1, 2000 Episode. ftp://ftp. tnrcc.state.tx.us /pub/OEPAA/TAD/Modeling/HGAQSE/Modeling/Doc/TSD P HASE1/attachment3-emissions_inventory.pdf.

Texas Natural Resource Conservation Commission (2002). Development of Source Speciation Profiles from the TNRCC 2000 Point Source Database. ftp://www.tnrcc.state.tx.us/pub/OEPAA/TAD/Modeling/HGAQS E/Contract Reports/EI/.

U.S. Environmental Protection Agency (1992). Users Guide for the Urban Airshed Model, Volume 4: User's Manual for the Emissions Preprocessor System 2.0, Part A: core FORTRAN system, EPA-450/4-90-007D(R) 